\title{
AGR-5/6/7 Fuel Fabrication Report
}

Douglas W. Marshall

May 2019

The INL is a

U.S. Department of Energy National Laboratory

operated by

Battelle Energy Alliance

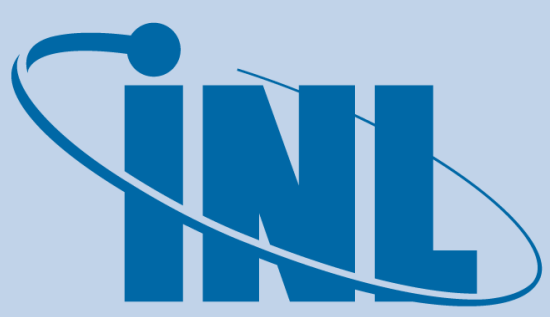

Idaho National Laboratory 


\section{DISCLAIMER}

This information was prepared as an account of work sponsored by an agency of the U.S. Government. Neither the U.S. Government nor any agency thereof, nor any of their employees, makes any warranty, expressed or implied, or assumes any legal liability or responsibility for the accuracy, completeness, or usefulness, of any information, apparatus, product, or process disclosed, or represents that its use would not infringe privately owned rights. References herein to any specific commercial product, process, or service by trade name, trade mark, manufacturer, or otherwise, does not necessarily constitute or imply its endorsement, recommendation, or favoring by the U.S. Government or any agency thereof. The views and opinions of authors expressed herein do not necessarily state or reflect those of the U.S. Government or any agency thereof. 
INL/EXT-19-53720

Revision 0

\title{
AGR-5/6/7 Fuel Fabrication Report
}

\author{
Douglas W. Marshall
}

May 2019

\begin{abstract}
Idaho National Laboratory
INL ART Program

Idaho Falls, Idaho 83415
\end{abstract}

http://www.inl.gov

Prepared for the

U.S. Department of Energy

Office of Nuclear Energy

Under DOE Idaho Operations Office

Contract DE-AC07-05ID14517 



\title{
INL ART Program \\ AGR-5/6/7 Fuel Fabrication Report
}

\author{
INL/EXT-19-53720 \\ Revision 0
}

May 2019

Author:

Douglas W. Marshall

Mithashall

AGR TRISO Fuel Fabrication Technical Lead Engineer

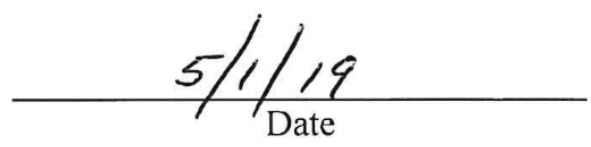

Technical Reviewer: (Confirmation of mathematical accuracy, and correctness of data and appropriateness of assumptions.)
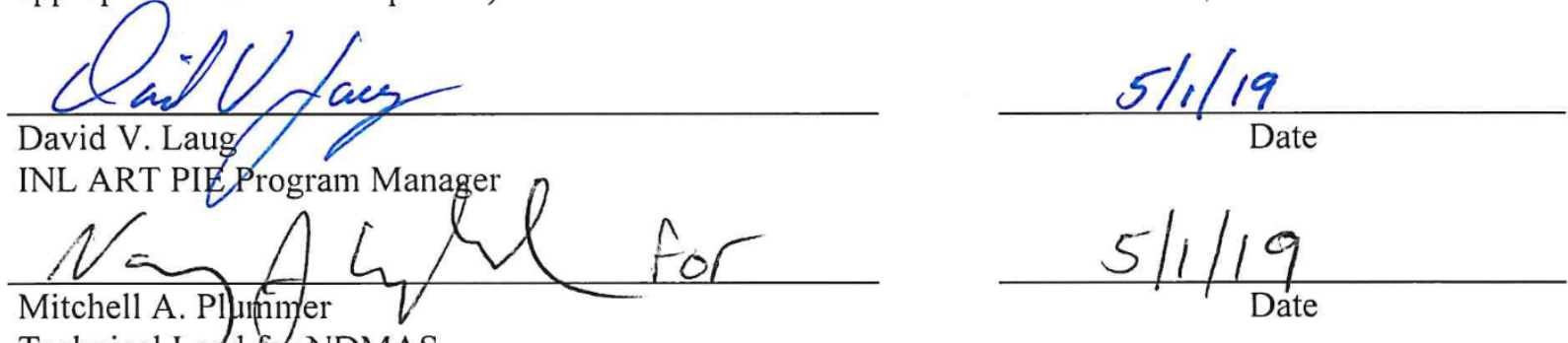

Technical Lead for NDMAS
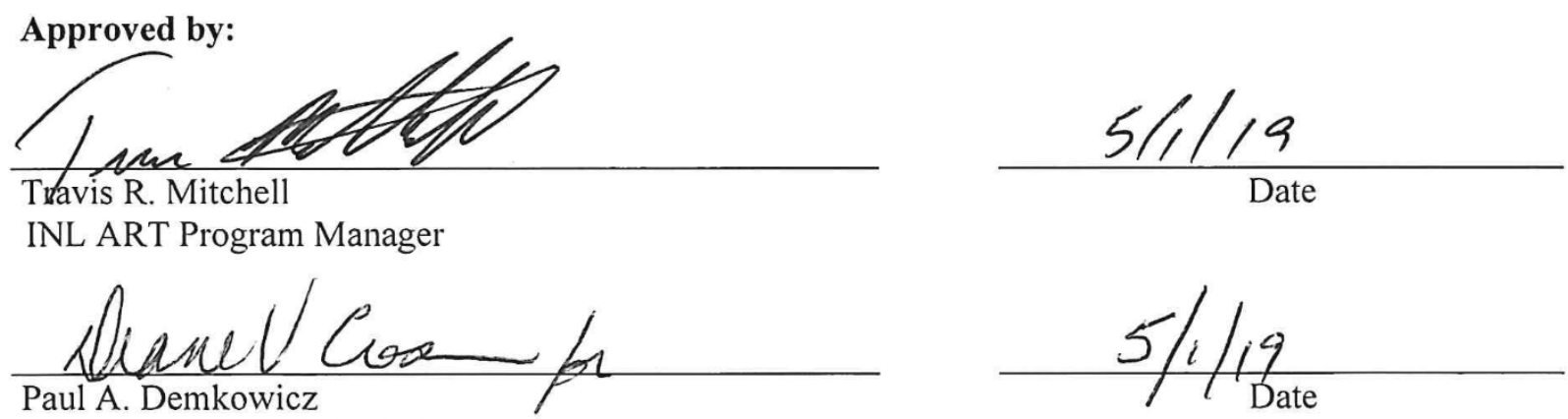

AGR Program Technical Director
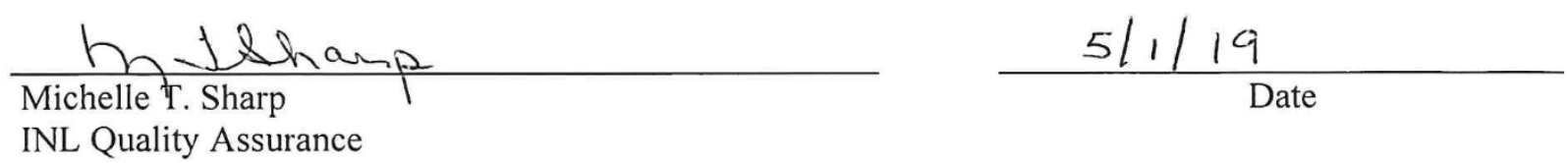



\section{REVISION LOG}

\begin{tabular}{|c|c|c|l|}
\hline Rev. & Date & Affected Pages & \multicolumn{1}{c|}{ Revision Description } \\
\hline 0 & $05 / 01 / 2019$ & All & New document. \\
\hline & & & \\
\hline & & & \\
\hline & & & \\
\hline & & & \\
\hline & & & \\
\hline & & & \\
\hline & & & \\
\hline & & & \\
\hline & & & \\
\hline & & & \\
\hline & & & \\
\hline & & & \\
\hline & & & \\
\hline
\end{tabular}





\section{Summary}

The Idaho National Laboratory (INL) Advanced Reactor Technologies (ART) program, under contract with the U.S. Department of Energy-Office of Nuclear Energy (DOE-NE), manages the Advanced Gas Reactor (AGR) Fuel Development and Qualification program (referred to as AGR Fuel program hereafter) in pursuing qualification of tristructural isotropic (TRISO) coated-particle fuel for use in high-temperature gas-cooled reactors (HTGRs). The AGR Fuel program was established to provide a fuel-qualification data set in support of the licensing and operation of an HTGR. BWX Technologies Nuclear Operations Group (BWXT-NOG) was subcontracted to fabricate the fuel for the AGR program.

\section{Innovations and Improvements}

Several investments in equipment and innovations were realized in preparation to fabricate fuel for the AGR-5/6/7 irradiation experiments that brought fuel fabrication fully out of the laboratory and into engineering-scale operations. These included:

- Increasing the kernel fabrication line capacity and uniformity of processing conditions

- Upgrading ancillary support equipment and processes for the TRISO coating furnace

- Demonstrating efficient production of the matrix precursor powder by dry-jet milling of co-mingled components

- Demonstrating an engineering-scale method for quick and efficient overcoating of TRISO particles with the matrix precursor

- Demonstrating an automated, multi-cavity compacting system with a volumetric feed system

- Demonstrating a combined-cycle thermal treatment furnace.

These changes increased production rates of some of these processes by an order of magnitude or more while eliminating the use of flammable solvents, multiple grinding and sorting operations, and the weighing out of individual die charges.

\section{Fuel Fabrication}

Three fuel-kernel lots were fabricated for production of fuel for AGR-5/6/7. The initial lot (J52R-16-39316) was certified to fuel specifications, but was not used because the kernels had a high fraction of internal fissures. This caused an unacceptable fraction of the kernels to fragment when charged to the coating furnace where the TRISO coating would be deposited. Fragmented kernels increased the dispersed uranium in the particles and produced an undesirable fraction of dimpled particles with an elevated probability of in-pile failure. After some efforts to identify the cause of the fissure formation, two additional lots were produced with much lower fissure fractions, J52R-16-69317 and 69318. The latter kernel lot was a backup to the first and was eventually not needed. Multiple kernel batches were composited to form each of the lots to simulate a commercial-scale operation.

Multiple TRISO coating runs were performed, and the product was characterized so that several could be composited into a TRISO lot. TRISO Lot J52R-16-98005 conformed to all fuel specifications except the mean outer pyrocarbon (OPyC)-layer thickness was thinner than specified. Furthermore, it was determined that the TRISO lot had a dispersed uranium fraction (DUF) that might result in the compacts not meeting the DUF specification. A review of the role of the OPyC layer and consequences of the DUF by the Technical Coordination Team and INL concluded that the fuel was acceptable for use in the AGR-5/6/7 irradiation experiment. ${ }^{\mathrm{a}}$

a Summary of Technical Coordination Team Videoconferences, dated February 1, 2017 and June 5, 2017. 
The TRISO particles were overcoated with a matrix precursor that had been produced in a jet-milling operation. The overcoating was performed in equipment originally designed to coat pharmaceuticals. The overcoating process performed well, producing highly spherical and uniform overcoats requiring little upgrading and no recycling or reworking. TRISO particles were overcoated with the matrix precursor to achieve nominal volumetric packing fractions (PFs) of TRISO particles of $25 \%$ and $40 \%$ for the irradiation experiments. The $40 \% \mathrm{PF}$ compacts occupy the first and fifth test capsule in the test train while the inner three capsules are loaded with $25 \%$ PF compacts.

The resonated-graphite matrix-precursor powder was a derivative of the German A3-27 matrix formulation, which differs from previous AGR irradiation campaigns that used an A3-3 formulation. Jet milling of the matrix powder precursor produced a finer mean graphite-particle size than the milling operations used for the A3-3 matrix powder precursor. Changes made in the matrix formula and equipment yielded compacts with significantly higher matrix density than was attained in previous AGR irradiation experiments. The changes in the matrix formulation and the means of milling the powders also complicated resolution of the three fuel-compact defect fractions, DUF, exposed-kernel fraction (EKF), and the silicon carbide defect fraction (SDF). Characterization data from BWXT-NOG had some anomalous results, so samples of the fuel compacts and overcoated TRISO particles were also analyzed by Oak Ridge National Laboratory (ORNL) to ensure that the defect fractions were accurately characterized.

As of this writing, the AGR-5/6/7 fuel compacts are being irradiated in the Advanced Test Reactor and appear to be performing as well as the fuel during the AGR-2 irradiation. 


\section{CONTENTS}

ACRONYMS xiii

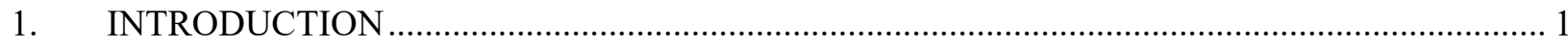

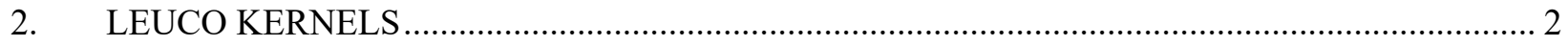

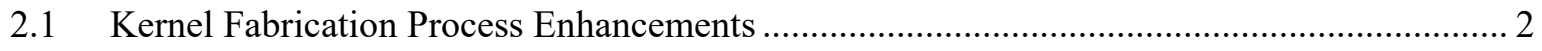

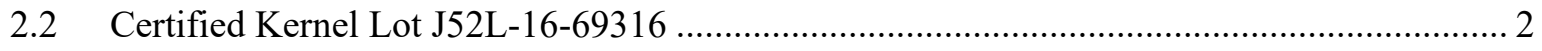

2.2.1 Batches Fabricated and Selected for Compositing............................................... 2

2.2.2 Fissured Kernels and Misshapen TRISO Particles ................................................. 3

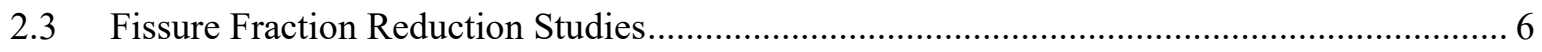

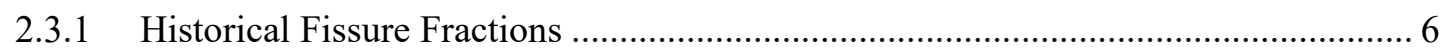

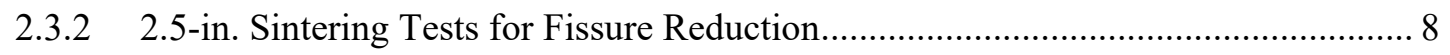

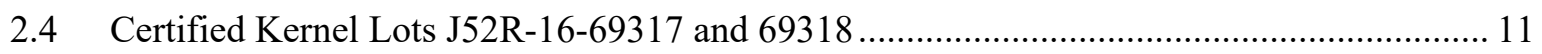

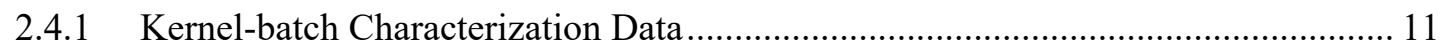

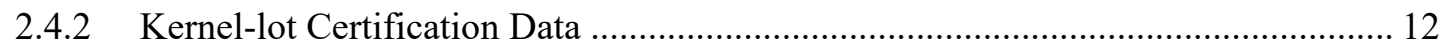

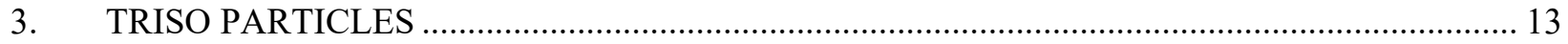

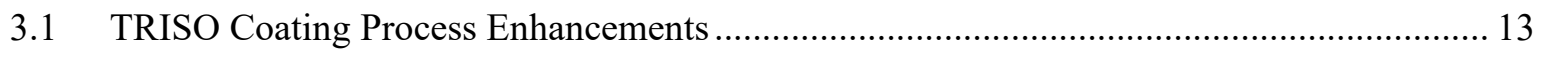

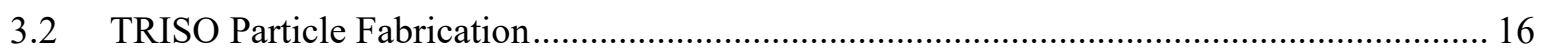

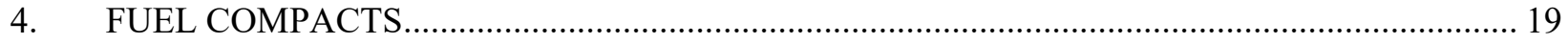

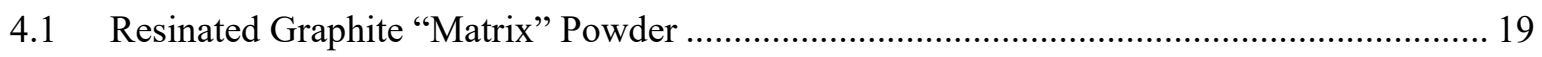

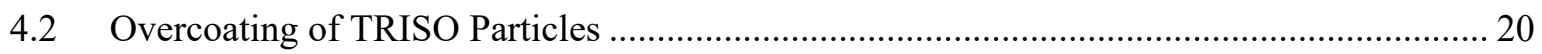

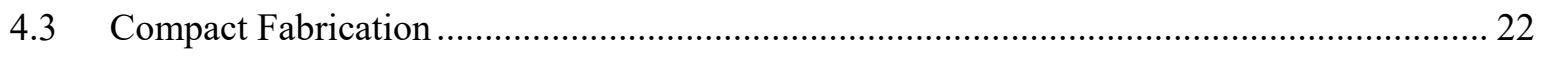

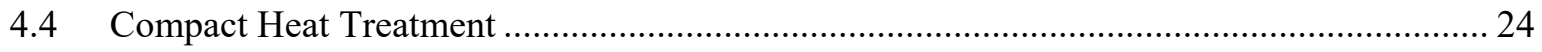

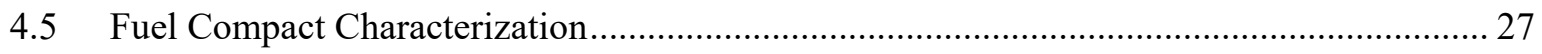

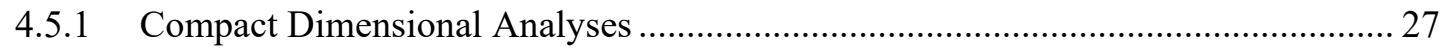

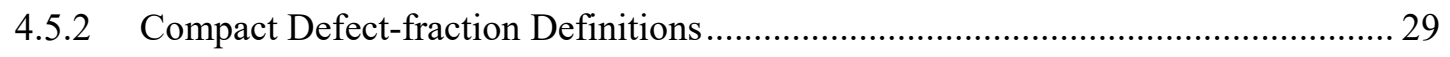

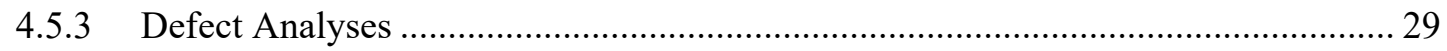

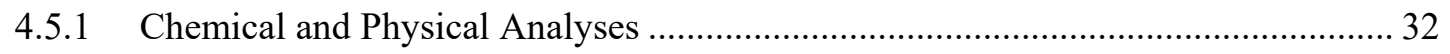

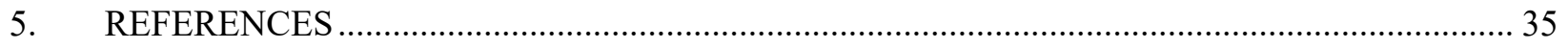

Appendix A Jet Pulverizer Co. Certificates of Analysis - Resinated Graphite Powder............................ 39

\section{FIGURES}

Figure 1. Polishing artifacts on LEUCO kernels showing (a) pressure cracks and (b) dislocations............. 3

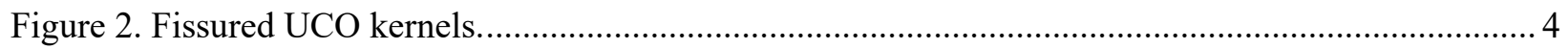

Figure 3. Misshapen TRISO particles: dimpled $(\mathrm{a}, \mathrm{b})$ and poly-kernel $(\mathrm{c})$.............................................. 4 


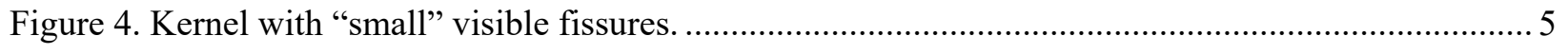

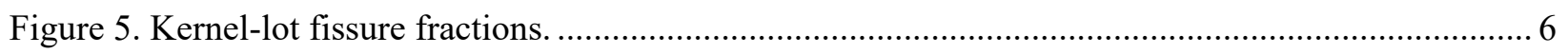

Figure 6. Fissured kernel exhibiting surface "scars" over fissures. ...................................................... 7

Figure 7. Rejected kernel fragments and shards by sieving.......................................................... 7

Figure 8. Kernel fissure fractions from the reduction study. ............................................................ 11

Figure 9. Polished and etched cross section of a TRISO particle showing a mid-radius SiC layer

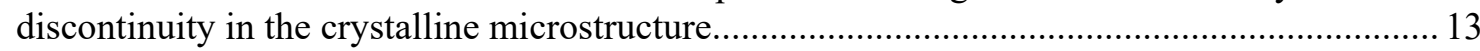

Figure 10. Former gas-distributor nozzle with a dimple pattern in the $\mathrm{SiC}$ accretions............................. 14

Figure 11. Chalice profiles for AGR-2 and subsequent coating runs. ................................................. 15

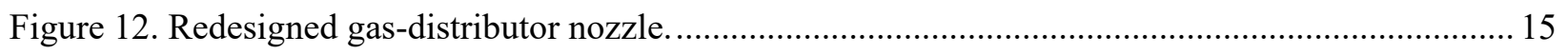

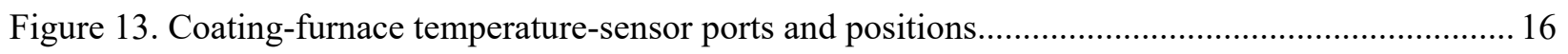

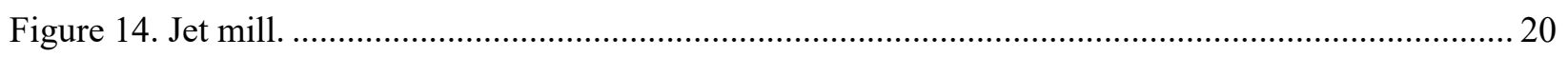

Figure 15. Illustration of the Freund-Vector Lab-3 Granuex equipment cross section. ...........................2 21

Figure 16. Example kernel map (X-ray CT) on a compact radial cross-section......................................22

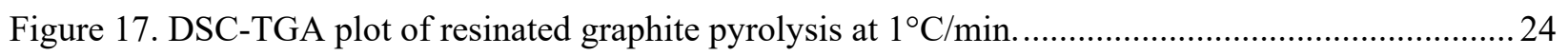

Figure 18. Furnace temperature ramp rate schedule.........................................................................2 25

Figure 19. Furnace temperature and calculated compact mass retention.................................................26

Figure 20. Photos of AGR-5/6/7 fuel compacts................................................................................ 27

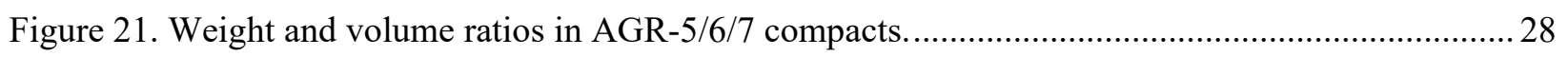

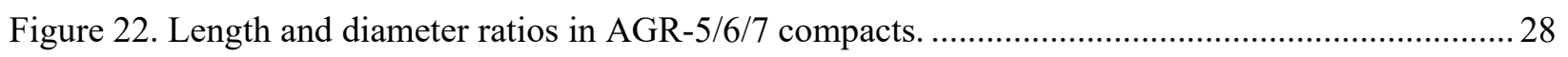

Figure 23. Compact and overcoated TRISO defect fractions quantified by ORNL. ................................ 31

Figure 24. Total uranium leached during defect characterizations by ORNL (treated as a variable

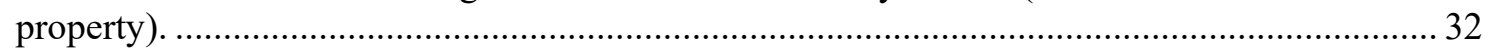

\section{TABLES}

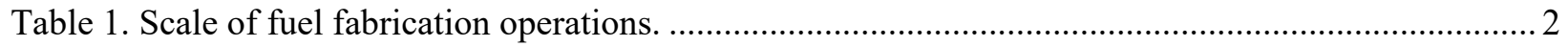

Table 2. LEUCO kernel batches fabricated for kernel lot J52L-16-69316 ............................................ 2

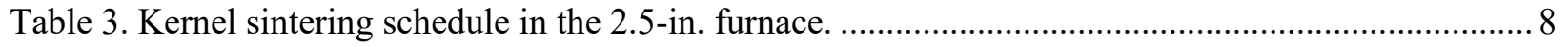

Table 4. Kernel fissure-reduction study with the 2.5-in. sintering furnace .............................................. 10

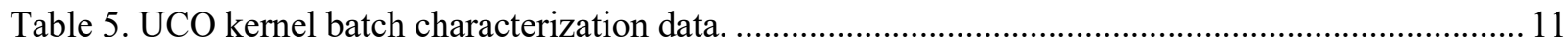

Table 6. AGR-5/6/7 certified UCO kernel lot characterization data....................................................... 12

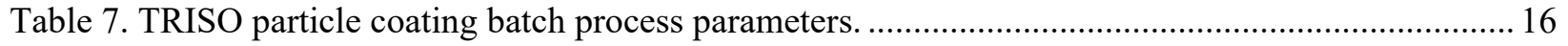

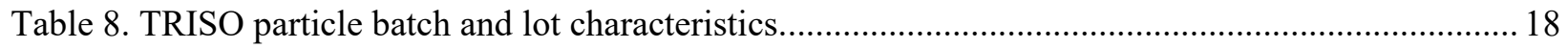

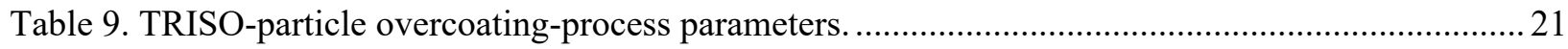

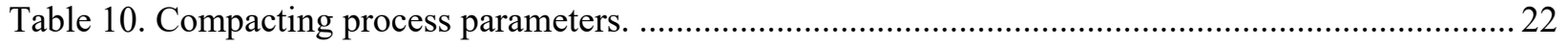


Table 11. AGR-compact furnace-temperature schedule. 26

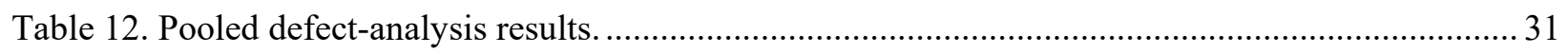

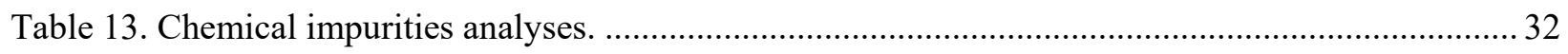

Table 15. Characterization data for nominally $25 \%$ PF compacts after heat treatment.......................... 35 


\section{ACRONYMS}

ADUN acid-deficient uranyl nitrate

AGR Advanced Gas Reactor

ART Advanced Reactor Technologies

ATR Advanced Test Reactor

BWXT BWX Technologies, Inc.

BWXT-NOG BWXT Nuclear Operations Group

DOE U.S. Department of Energy

DOE-NE DOE, Office of Nuclear Energy

DSC-TGA Differential Scanning Calorimetry - Thermogravimetric analysis

DUF dispersed-uranium fraction

EKF exposed-kernel fraction

HMTA hexamethylenetetramine

HTGR high-temperature gas-cooled reactor

INL Idaho National Laboratory

IPyC inner pyrolytic carbon (pyrocarbon) layer

LEU low-enriched uranium

LEUCO low-enriched uranium carbide/oxide mixed ceramic

LL lower limit

MTS methyltrichlorosilane

MW molecular weight

OPyC outer pyrocarbon layer

ORNL Oak Ridge National Laboratory

$\mathrm{PF} \quad$ (volumetric) packing fraction

PIE post-irradiation examination

PLC programmable logic controller

ppmw parts per million by weight

SDF silicon carbide defect fraction

TCE trichloroethylene

TCT technical coordination team

TRISO tristructural isotropic

UCO uranium carbide/oxide mixed ceramic

UL upper limit 


\section{AGR-5/6/7 Fuel Fabrication Report \\ 1. INTRODUCTION}

The U.S. Department of Energy-Office of Nuclear Energy (DOE-NE) and the Idaho National Laboratory (INL) Advanced Reactor Technologies (ART) Advanced Gas Reactor (AGR) Fuel Development and Qualification program (hereafter referred to as AGR Fuel Program) are pursuing qualification of tristructural isotropic (TRISO) coated particle fuel for use in high-temperature gas-cooled reactors (HTGRs). The AGR Fuel Program was established to provide fuel qualification data in support of licensing fuel for an HTGR. A multi-capsule test train was established, combining the AGR-5, AGR-6, and AGR-7 (AGR-5/6/7) experiments, which are being simultaneously irradiated in the northeast flux trap position in the Advanced Test Reactor (ATR). The fuel is being tested, demonstrated, and qualified under service conditions enveloping normal and off-normal operating conditions and subsequently safety tested during post-irradiation examination (PIE).

Fuel fabrication development spans the irradiation and PIE of all the AGR experiments. Advances in fuel-fabrication development for the AGR-5/6/7 fuels included:

- Enhancements to the low-enriched uranium carbide/oxide (LEUCO) kernel fabrication process equipment

- An improved resonated-graphite powder production process via dry-jet milling of comingled components

- An improved overcoating process using a fluidized-bed overcoater

- An automated, multi-cavity compacting press with a volumetric feeder system

- A combined-cycle carbonization and heat-treatment furnace.

The AGR-5/6/7 fuel components were not produced from single batches, but as multiple batches blended into lots to simulate industrial fabrication methods while using prototypic or engineering-scale equipment. Compacts were fabricated with the two volumetric particle packing fractions, nominally $40 \%$ and $25 \%$, with the compacts of the higher packing fraction installed in the two end capsules of the test train assembly (i.e., Capsule 1 and Capsule 5) and the compacts of the lower packing fraction in the central capsules to facilitate the control of fuel temperatures.

The AGR-5/6 portion of the test train will provide irradiated-fuel performance data and irradiated-fuel samples for safety testing and PIE in sufficient quantity to demonstrate compliance with statistical performance requirements. The AGR-7 portion is a "margin" test to collect data from fuel pushed beyond its normal-operating-temperature envelope to demonstrate the capability and limitations of the fuel to withstand extreme conditions in support of plant design and licensing.

Development activities focused on the transfer of technologies from national laboratories to the commercial sector, moving from laboratory-scale to engineering-scale equipment (Table 1) and defining, developing, refining, and deploying processes for fuel fabrication that eliminate waste streams, hazardous solvents, and rework while reducing labor and increasing process automation. Including an automated press for forming the fuel compacts with a volumetric particle feeder eliminated the need to weigh out individual die charges and greatly increased productivity.

The only analytical technique that has not been effectively transferred to BWX Technologies Nuclear Operations Group (BWXT-NOG) is the high-resolution X-ray imaging necessary to detect uranium migration within a TRISO particle as a metric for a defective inner pyrolytic carbon (IPyC) layer. This technology is, however, readily available should BWXT-NOG elect to fabricate TRISO particles on a commercial scale at some future date. 
As of this writing, the AGR-5/6/7 fuel compacts are being irradiated in the Advanced Test Reactor and appear to be performing as well as the fuel used for the AGR-2 irradiation.

Table 1. Scale of fuel fabrication operations.

\begin{tabular}{|l|l|l|l|l|}
\hline \multicolumn{1}{|c|}{ Fabrication Step } & \multicolumn{1}{c|}{ AGR-1 } & \multicolumn{1}{c|}{ AGR-2 } & \multicolumn{1}{c|}{ AGR-3/4 } & \multicolumn{1}{c|}{ AGR-5/6/7 } \\
\hline Kernel fabrication & Engineering & Engineering & Engineering & Engineering \\
\hline TRISO coating & Lab & Engineering & Lab & Engineering \\
\hline $\begin{array}{l}\text { Resinated graphite } \\
\text { powder fabrication }\end{array}$ & Lab & Lab & Lab & Engineering \\
\hline Particle overcoating & Lab & Lab & Lab & Engineering \\
\hline Compact fabrication & Lab & Lab & Lab & Engineering \\
\hline
\end{tabular}

\section{LEUCO KERNELS}

\subsection{Kernel Fabrication Process Enhancements}

Following the fabrication of kernels for the AGR-2 experiment, a few process enhancements were made to improve throughput capacity and process control. These modifications included:

- Upgrading the control system of the sintering furnace with a modern programmable logic controller (PLC)

- Modernizing and increasing the capacity of the uranium dissolvers and down-blending vessels

- Adding more sol-gel sphere-collection and drying stations to increase the throughput of the kernel line

- Installing individual heater controls for the sol-gel drying stations to ensure that all stations had similar temperature exposures and drying rates for improved quality control.

These enhancements significantly increased the throughput capacity of the acid-deficient uranyl nitrate (ADUN) and kernel-forming lines. The PLC increased process reliability because it replaced the antiquated controller that had shared an indispensable and irreplaceable computer card with the old TRISO coating furnace controller, which had to be physically moved, as needed, between processes. Upgrading the controllers enabled simultaneous operation of the kernel-sintering furnace and the TRISO coating furnace, although this ability was not exploited.

\subsection{Certified Kernel Lot J52L-16-69316}

\subsubsection{Batches Fabricated and Selected for Compositing}

Six batches of sintered LEUCO kernels were prepared for use in the certified kernel Lot J52L-16-69316, designated as J52L-16-59515 through 59520, which yielded $17.7 \mathrm{~kg}$ of kernels. When the isotopic analyses were performed, it was found that the last two batches were low in enrichment. The cause was traced to undissolved uranyl nitrate crystals in the blending containers that were then dissolved and added back into the acid-deficient uranyl nitrate solutions used in forming the kernels. The residual crystals were, apparently, composed of natural uranium, and their inclusion caused the ADUN and kernels to fall below the allowable enrichment as given in the fuel specification. ${ }^{1}$

Table 2. LEUCO kernel batches fabricated for kernel lot J52L-16-69316.

\begin{tabular}{|c|c|c|c|c|}
\hline Kernel Batch & Enrichment (\%) & Quantity Available (g) & Quantity Used (g) & Residue (g) \\
\hline J52-16-59515 & 15.421 & $3,345.8$ & $3,345.8$ & 0.0 \\
\hline J52-16-59516 & 15.439 & $3,108.0$ & $3,108.0$ & 0.0 \\
\hline
\end{tabular}




\begin{tabular}{|c|c|c|c|c|}
\hline Kernel Batch & Enrichment (\%) & Quantity Available (g) & Quantity Used (g) & Residue (g) \\
\hline J52-16-59517 & 15.447 & $2,686.1$ & $2,686.1$ & 0.0 \\
\hline J52-16-59518 & 15.429 & $3,112.6$ & $3,112.6$ & 0.0 \\
\hline J52-16-59519 & 15.378 & $2,768.6$ & 450.0 & $2,318.6$ \\
\hline J52-16-59520 & 14.948 & $2,707.4$ & 0.0 & $2,707.4$ \\
\hline Totals & - & $17,728.5$ & $12,702.5$ & $5,026.0$ \\
\hline
\end{tabular}

In order to ensure that at least $12 \mathrm{~kg}$ of certified kernels were available after blending and sampling for characterization of the lot, $450 \mathrm{~g}$ of Batch J52-16-59519 were included in the blend, despite not conforming to the minimum enrichment. The blend, however, did meet all fuel specifications. ${ }^{2}$

\subsubsection{Fissured Kernels and Misshapen TRISO Particles}

2.2.2.1 Discovery. A sample of each kernel batch and kernel lot is potted in resin, ground almost to the equatorial plane, and subsequently polished to expose the inner portion of the kernels so that the distribution of the carbidic and oxidic phases can be observed. Various internal defects and "mounting artifacts" were observed when micrographs of the mounts were prepared and examined. Mounting artifacts included cracked kernels (Figure 1a) and kernels with dislocations (Figure 1b), which may indicate a low crush strength, but are of no known consequence to fuel performance once the kernels are TRISO-coated.

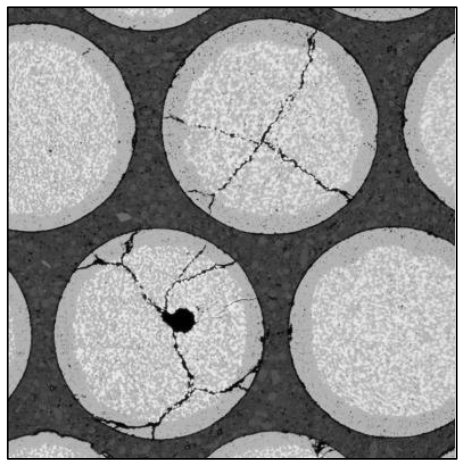

(a)

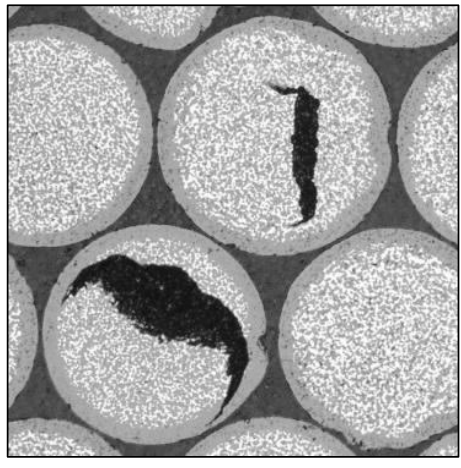

(b)

Figure 1. Polishing artifacts on LEUCO kernels showing (a) pressure cracks and (b) dislocations.

Internal kernel defects, however, may have consequences adverse to quality. These defects are fissures (surface-connected cracks) that formed in the kernel sometime between gel forming and the kernel sintering. The hallmark of a fissured kernel is the presence of an oxidic phase in the kernel interior that outlines the surface-connected fissure (Figure 2). 


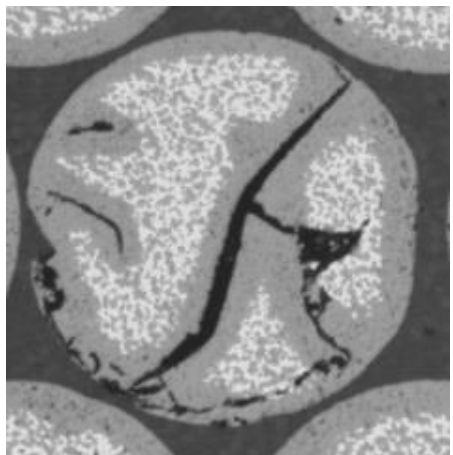

(a)

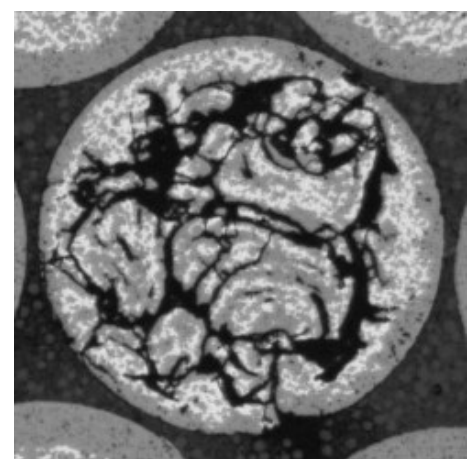

(b)

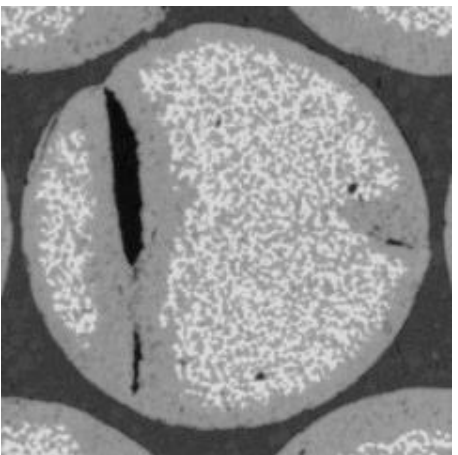

(c)

Figure 2. Fissured UCO kernels.

2.2.2.2 Consequence. After multiple reviews by the Technical Coordination Team, ORNL, and INL personnel, it was concluded that the presence of surface-connected fissures in the kernel would not adversely affect the outcome of an irradiation experiment provided that the fissures did not adversely impact the TRISO particle coating processes. That conclusion was based on the perspective that kernels undergo morphological changes during irradiation that are more pronounced than the fissures and the presence of the fissures did not cause a significant reduction in the uranium content of the affected kernel.

A TRISO coating run (Run J52O-16-93159) was performed using the certified kernel lot (Lot J52L-16-69316), which had a high fissured-kernel fraction. Upon examination of the product, it was noted that the fractions of dimpled particles and poly-kernel particles had increased markedly relative to previous process-development runs with natural uranium (Figure 3 ).

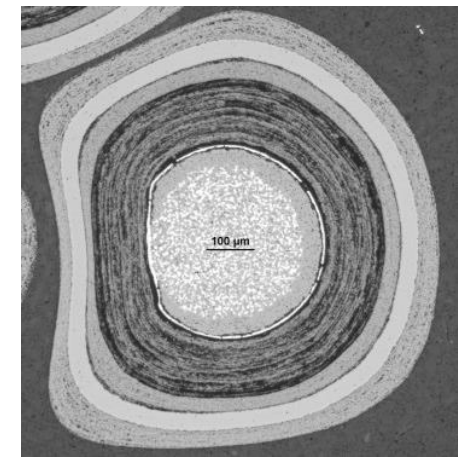

(a)

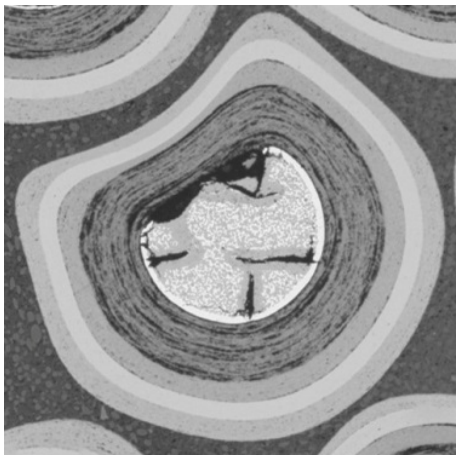

(b)

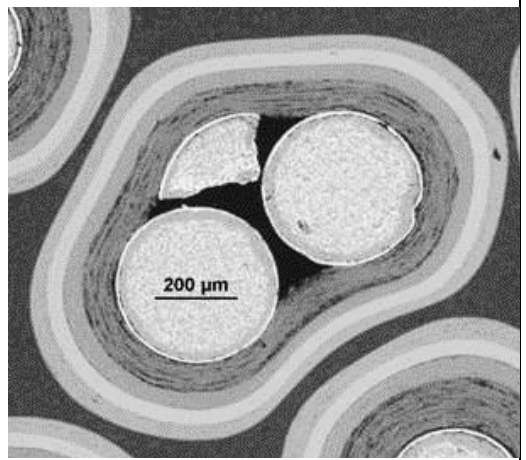

(c)

Figure 3. Misshapen TRISO particles: dimpled $(a, b)$ and poly-kernel (c).

Some fissured kernels fractured after being charged to the coating furnace for the TRISO coating run. Larger broken-kernel fragments resulted in "dimpled" TRISO particles (Figure 3[a] and [b]). Wedge-shaped fragments can became individually coated or they can form poly-kernel particles (Figure 3[c]). Exposed carbidic phases on fractured surfaces apparently fuse with the oxidic exteriors of adjacent kernels in the bed to form a poly-kernel cluster before the buffer layer is deposited.

Undersized particles containing a wedge-shaped kernel fragment may be rejected by sieving if the minor dimensions are small relative to whole particles. The poly-kernel particles are not desired, but there is no recognized reason why they should not perform well under irradiation. Furthermore, the long aspect of the poly-kernel particles make them easy to reject by sieving, especially after applying an overcoat of resonated-graphitic matrix precursor, which causes them to be substantially oversized relative to TRISO particles containing a single kernel. 
As kernels fracture or their surfaces spall, small fragments and dust particles are liberated that can become incorporated into the coating layers. This fugitive or "dispersed" uranium can increase the probability of fission-product release and the potential for damage to the silicon carbide layer.

Efficient segregation of dimpled particles from the normally shaped population is presently unattainable. These particles present a similar particle size, density, and shape as the desirable TRISO particles. Attempts were made to segregate the dimpled particles by sieving, roller micrometry, density flotation, and using a vibrating inclined table. None proved to be both effective and efficient.

Furthermore, no means have been identified or tested to reject the fissured kernels from the kernel lot.

The dimpled particles present two features that are adverse to performance during irradiation and could compromise the outcome of an irradiation experiment. These features include an unacceptable thinning of the coating layers in the dimple crater and the short radius of curvature along the rim. The thin layers are not adequate barriers against fission-product release and their weakened strength, combined with stress concentration along the rim, could lead to increased failure fractions under irradiation and during safety testing (i.e., simulated loss-of-coolant accident conditions).

Without a viable means of rejecting dimpled particles from the TRISO product and noting the strong relationship between the kernel fissure fraction and the incidence of dimpled particles, the decision was made to cease using LEUCO kernel Lot J52L-16-69316, with its countable fissure fraction of $6.6 \%(8.8 \%$ at $95 \%$ confidence) and fabricate a new kernel lot for use in the AGR-5/6/7 experiments.

2.2.2.3 Fissure Classification. Classification of the fissure severity is difficult when using a twodimensional (2-D) slice of a three-dimensional (3-D) feature. One cannot reliably ascertain whether the fissures are shallow or if they penetrate deeply into the kernel when all that is observed are small fissures on the perimeter of the particle. An example is shown in Figure 4. The shallow fissures appear as though they might connect outside of the exposed plane, but they could also be independent. Furthermore, the depth of the fissure beyond the visible plane can differ significantly from what is observed. A metric was needed to quantify the fissured-kernel fraction and to compare kernel lots. The following definitions were devised, which, although imperfect, achieved the objective.

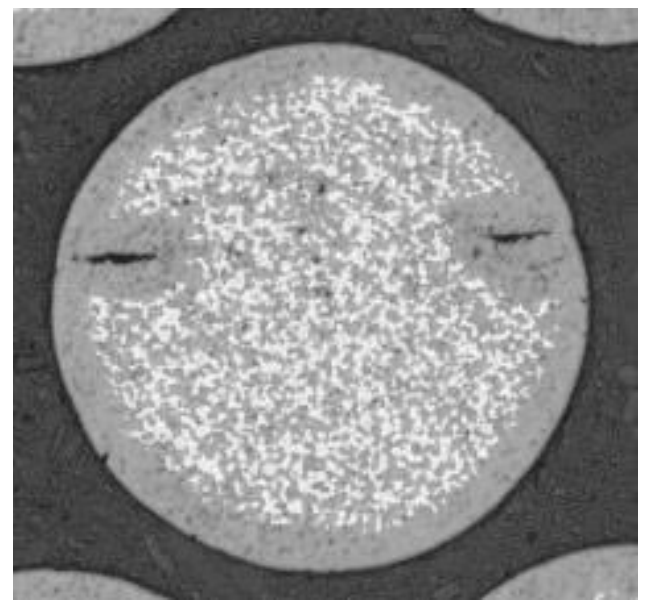

Figure 4. Kernel with "small" visible fissures.

Fissure: A surface-connected void that is lined by an oxidic phase and clearly extends below the mean radius of the oxidic rind. By "clearly" is meant that it is discernable without the use of tools to measure the oxidic rind thickness or the length of the exposed void. The presence of the oxidic rind around the fissure is evidence that the fissure is (or was) surface connected.

Countable Fissure: A countable fissure is one that terminates within the oxidic rind at two or more positions along the kernel perimeter (Figure 2). This could be a visible fissure and/or its oxidic lining that 
transects the kernel (Figure 2c), a fissure that branches within the kernel, intersects another fissure within the kernel, or forms an arc that returns to the kernel surface.

It is presumed that kernels with only shallow fissures will not fracture when charged to the fuel coater. Those that are extensively fissured (i.e., countable) are thought to be more prone to fracturing and becoming a source of misshapened particles and resulting in dispersed uranium contamination within the coating layers. Batch-to-batch and lot-to-lot comparisons are done primarily by the "countable" fissure fraction. The total fissure fraction is also reported as it could prove significant in the future.

\subsection{Fissure Fraction Reduction Studies}

\subsubsection{Historical Fissure Fractions}

The fissure fraction within any UCO kernel batch seems to have a stochastic nature (Figure 5). One or more causal factors remain uncontrolled and unidentified in the fabrication process. One could speculate that the "age" of the acid-deficient uranyl nitrate solutions, the presence of microcrystalline particulates, microbubbles, or dissolved gases in the aqueous solutions may influence the product. No data exist in our program to either prove or disprove these hypothetical factors. The prominent hypotheses, at this time, are related to crystallite sizes, which influences pore diameters and pore volumes within the gel. The color of the gel (orange or yellow) ${ }^{3}$ is an indicator of the crystallite size when no carbon is present. Carbon black was added to the broth to form carbides during the carbothermic-reduction phase of thermal treatment, but the carbon results in an opaque, black gel and prevents discerning kernel crystallite sizes by color. All of the kernel lots shown in Figure 5 were made with natural uranium except for 69307, fabricated for AGR2, and 69316-69318 that were fabricated for AGR-5/6/7. These exceptions were fabricated using enriched uranium of $14 \%$ and $15.5 \%$, respectively. Uranium enrichment does not correlate with the kernel fissure fraction.

\section{UCO Kernel Lot Fissure Fractions}

(with $\pm 95 \%$ single-sided confidence limits)

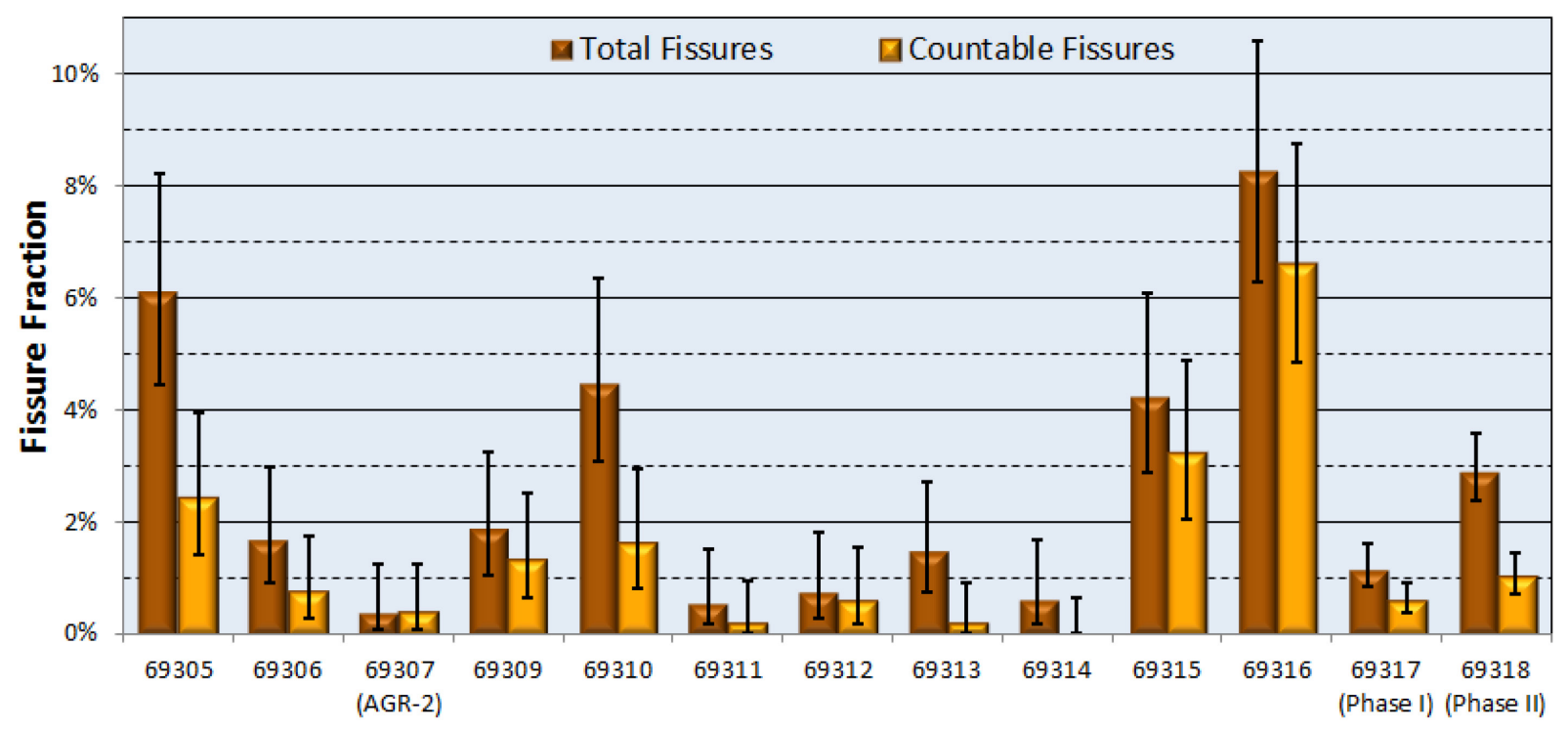

Figure 5. Kernel-lot fissure fractions.

The pore diameters and volumes influence internal capillary pressures during drying, as the aqueous menisci retreat into the pores, and how effectively the gels can be "washed" to remove solutes, such as 
urea, hexamethylenetetramine (HMTA), and ammonium nitrate. These solutes decompose at relatively low temperatures during thermal treatment subsequent to the initial gel shrinkage from dehydration.

One hypothesis is that internal pressures, either from capillary pressure from pore water or pressurization during solute decomposition, exceed the hoop strength of the gel surface; causing ruptures to occur that become the surface-connected fissures. During the sintering phase of thermal treatment, the kernel densifies, and fissure edges curl inward and often fuse at the surface (Figure 6), which is why the fissures may not appear to be surface connected (Figure 4) in sectioned kernels. A significant portion of the more severely fissured kernels will fracture during kernel sintering; the majority of these are subsequently rejected from the kernel batch during tabling and sieving of the kernel batches (Figure 7).

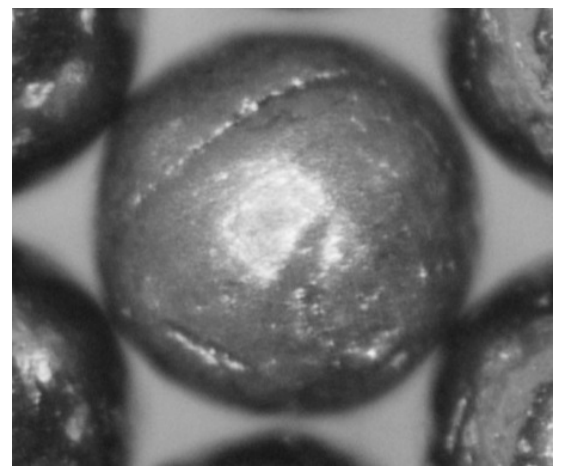

Figure 6. Fissured kernel exhibiting surface "scars" over fissures.

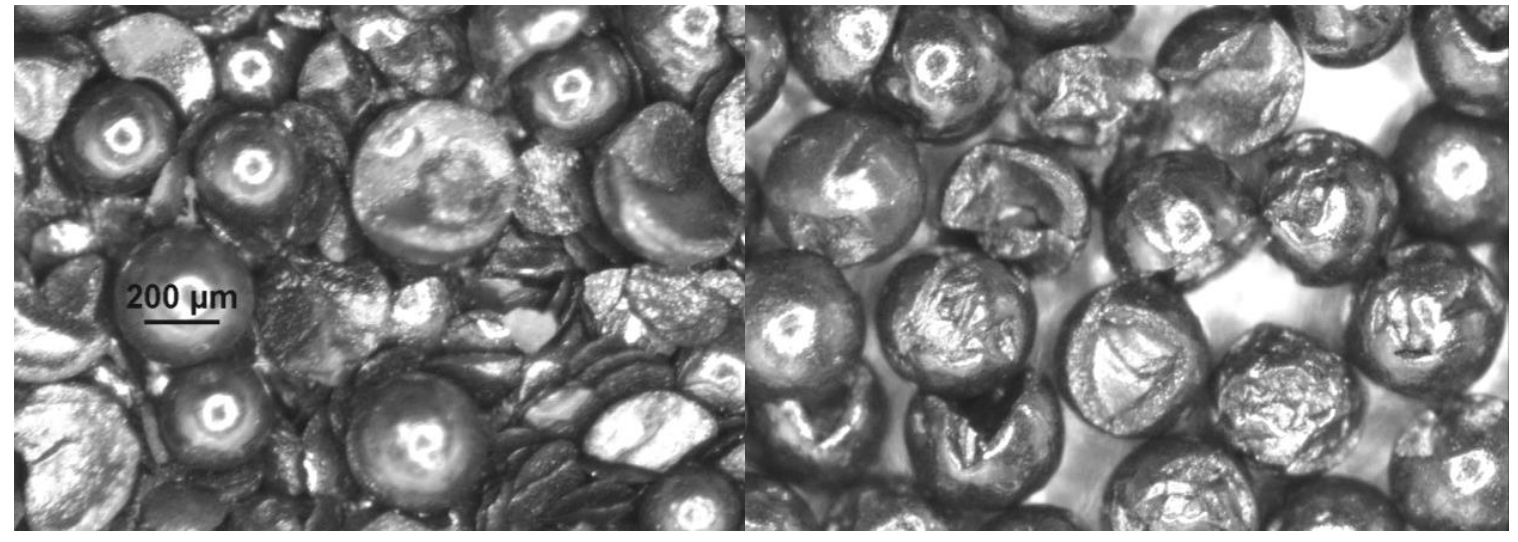

Figure 7. Rejected kernel fragments and shards by sieving.

An effort was made to identify a means of reducing the incidence of kernel fissuring during the manufacture of the kernels by conducting a series of smaller-scale tests using the 2.5 -in. sintering furnace at BWXT, rather than committing large quantities of kernels in the 6-in. sintering furnace. Because materials produced during the smaller-scale tests used equipment and procedures not representative of the product line with the 6-in. sintering furnace, the test product was not included in the composited LEUCO kernel lots. ${ }^{\mathrm{b}}$

b. Even though the same temperature schedule and gas compositions are used in the 2.5-in. sintering furnace runs as is used in the 6 -in. furnace runs, carbon retention is higher in the product from the 2.5 -in. furnace, and the relative quantity of uranium dicarbide is more favorable. The $[\mathrm{C}]:[\mathrm{U}]$ ratio in the 2.5 -in. furnace product was near 0.44 while the ratio from the 6in. furnace product was typically 0.38 . 


\subsubsection{5-in. Sintering Tests for Fissure Reduction}

Test cases were conducted to assess the impact of various parameter changes on the incidence of kernel fissuring. These cases included 1) a baseline case using the normal operating parameters;2) an extended wash-cycle case to ensure thorough solute removal; 3) cases with cool-air drying of the gels to reduce the rate of stress accumulation as the water menisci retreat into the pores; 4) cases with increased gas-flow rates during the calcination phase of thermal treatment to ensure better fluidization and to lower the dispersion in the temperature histories of individual kernels within a batch; and 5) cases with surfactant added to the wash solution to reduce the surface tension in the pores (reducing capillary pressures by about half) and encouraging larger diameter pores. ${ }^{4}$

For an unknown reason, all of the tests, including the baseline cases, produced kernels with very low fissure fractions, which resulted in inconclusive results regarding the effectiveness of any trial case for fissure reduction. Kernel batches processed using baseline conditions in the 6-in. sintering furnace exhibited a higher, yet acceptable, fissure fraction in most cases. Details on the various test cases are given for future reference.

2.3.2.1 Baseline. Broth-mixing ratios, broth pot temperature, broth-feed rate, forming needlesonication parameters, forming fluid temperature, forming fluid-recirculation rate (which affects gel residence time in the forming column), and gel "aging" in the collection pots were kept constant and consistent for all tests, with only minor and typical process variabilities. None of these variabilities in solution concentrations or process controllers are presently recognized as potential causal factors for kernel fissures.

Baseline gel washing involved draining the trichloroethylene (TCE) forming fluid from the collection pot and "washing" the gels with 1-wt \% ammonia water. The electrical conductivity of the virgin wash was measured with a probe, and washing was continued until the rinsate conductivity fell within a prescribed offset from the virgin fluid. The ammonia water leached out excess urea, HMTA, and their byproduct, ammonium nitrate salt. The presence of excess ammonium ion in the wash liquid ensures complete gelation of the uranium compounds. The duration of a typical wash cycle was about 30-45 minutes.

Baseline drying involved passing instrument air through the gel sphere bed in the collection pot. The air was heated and controlled to $70^{\circ} \mathrm{C}$ for each individual pot. Heated air flowed for 12 hours followed by 3-4 hours of unheated air flow until the operating crew returned in the morning.

The baseline thermal treatment of the dried gels followed the schedule outlined in Table 3 .

Table 3. Kernel sintering schedule in the 2.5-in. furnace.

\begin{tabular}{|l|c|c|c|c|c|}
\hline \multicolumn{1}{|c|}{ Step } & $\begin{array}{c}\text { Temperature } \\
\text { Ramp } \\
\left({ }^{\circ} \mathbf{C} / \mathbf{m i n}\right)\end{array}$ & $\begin{array}{c}\text { Endpoint } \\
\text { Temperature } \\
\left({ }^{\circ} \mathbf{C}\right)\end{array}$ & $\begin{array}{c}\text { Temperature } \\
\text { Hold (min) }\end{array}$ & $\begin{array}{c}\text { Gas } \\
\text { Composition }\end{array}$ & $\begin{array}{c}\text { Total Gas } \\
\text { Flow (slpm) }\end{array}$ \\
\hline Charging & NA & Ambient & NA & $100 \% \mathrm{Ar}$ & 10 \\
\hline Dehydration & 4 & 100 & 1 & $100 \% \mathrm{Ar}$ & 13 \\
\hline Calcination & $4^{\mathrm{a}}$ & 550 & 75 & $\begin{array}{c}94 \% \mathrm{Ar} \\
6 \% \mathrm{H}_{2}\end{array}$ & 13 \\
\hline $\begin{array}{l}\text { Carbothermic } \\
\text { Reduction }\end{array}$ & 40 & 1680 & 60 & $100 \% \mathrm{Ar}$ & 13 \\
\hline $\begin{array}{l}\text { Sintering } \\
\text { a. A temperature "excursion" reportedly occurs when indicated bed temperature is about } 400 \pm 50^{\circ} \mathrm{C}, \text { causing a rapid, } \\
\text { uncontrolled temperature rise. }\end{array}$ \\
\hline
\end{tabular}


2.3.2.2 Extended Gel Washing. Extended washing was accomplished by washing the gels until the normal termination criterion (i.e., the electrical conductivity offset) was met and then continuing the wash for an additional 45 minutes - roughly doubling the wash period. The hypothesis of this test is that the washing may have been incomplete, especially when pore diameters/volumes are small and that residual solutes increase the volume of gas generated during the early stages of thermal treatment while the gel is more vulnerable.

The only test with an extended wash cycle produced no countable fissured kernels in the population (Table 4, Figure 8).

2.3.2.3 Slow Drying of Gels. Slow drying of gels was accomplished by drying the gels with unheated instrument air. The hypothesis was that the kernels might shrink too rapidly, especially on the surface, when dried with heated air. The drying period was extended, as needed, to ensure that the gels were thoroughly dried.

The two tests using cool-air drying produced inconsistent results, so slow (cool-air) drying is ineffective in reducing the fraction of fissured kernels in the population.

2.3.2.4 Calcination with Increased Gas Flow. During thermal treatment in the sintering furnace, the uranium hydroxide hydrates decompose to form uranium trioxides in a process known as calcination. Calcination is followed by carbothermic reduction and sintering as treatment temperatures continue to rise.

Published correlations for calculating the minimum spouting velocity of a gas through a bed of solids were formulated from data collected on systems that did not have the high temperatures or exotic fluidizing gases that were used for thermally treating UCO kernels. Nonetheless, the correlations generally indicated that the system was not spouted below about $550^{\circ} \mathrm{C}$ because of insufficient fluidizinggas flow. Simulations made of the process at various static particle conditions, using computational particle fluid dynamics Barracuda VR software, confirmed that spouting would not occur until bed temperatures were about $400^{\circ} \mathrm{C}$. These calculated temperatures roughly correspond to the recorded process temperatures when BWXT-NOG personnel observed "thermal excursions" on temperature instruments, which may be the combined effect of a sudden onset of mixing (with the associated increased heat transfer) and exothermic calcination of previously "cold" kernels in the stagnant bed.

Tests were conducted with enhanced gas-flow rates while the bed was at the lower processing temperatures to test whether the onset of spouting at a lower temperature might reduce the incidence of kernel fissuring. Normal gas-flow rates during calcination were $12.2 \mathrm{slpm} \mathrm{Ar}$ with $0.8 \mathrm{slpm} \mathrm{H}_{2}(13$ slpm combined flows) while the enhanced gas flow used $37.6 \mathrm{slpm} \mathrm{Ar}$ with $2.4 \mathrm{slpm} \mathrm{H}_{2}$ (40 slpm combined flows). The combined gas flow rate was still too low to spout the gels at room temperature. The enhanced gas flow was near the maximum capacities of the flow meters and could not be increased without modifying the system. The superficial gas velocity in the 2.5 -in. furnace is 1.5 times higher than the superficial gas velocity in the 6-in. sintering furnace under baseline flow conditions and 4.6 times higher under the enhanced gas-flow conditions.

Increased gas flow was tested twice: once as the sole change to the procedure and once in combination with surfactant addition to the wash liquid. In both tests, no countable fissures were observed in either population.

2.3.2.5 Surfactant Addition to the Wash Liquid. TWEEN 20 is a highly pure, non-hazardous, non-ionic surfactant that lowers surface tension with small additions to aqueous systems. The addition of TWEEN 20 to a concentration in the range of $0.026-0.029 \mathrm{wt} \%$ should have reduced surface tension of the wash water approximately by half. A reduction in surface tension reduces the compressive forces on the gel surface, which helps keep pore diameters larger, and also reduces the capillary pressure in proportion to the reduction in surface tension. The combination of keeping the pores diameters larger 
(improved washing) and reduced capillary pressures were expected keep the gels from splitting during the drying cycle.

The fissured-kernel fractions from the two trials were not lower than other process changes, except when combined with a higher fluidizing gas-flow rate.

2.3.2.6 Conclusions. Variability of the outcomes due to stochastic kernel batch differences could not be accounted for and casts some doubt on the interpretation of the outcomes. The baseline case did not produce a high fissure fraction, as occurred in Kernel Lot J52L-16-69316, so no definitive, statistically valid conclusions can be drawn on methods to reduce kernel fissuring (Table 4, Figure 8). Increasing the gas flow rate during calcination, to achieve fluidization at a lower temperatures, appears to reduce kernel fissuring and should be further investigated. Given that the superficial gas flows were several times higher in the 2.5 -in. sintering furnace under enhanced flow conditions relative to the production-scale sintering furnace, and no fissures were detected in the product, higher gas flows should be considered for the production furnace when operating at lower temperatures to ensure adequate fluidization.

An extended gel-wash period is the only other condition tested by itself where no fissures were counted, but no statistically supported assertions can be made regarding its effectiveness. It would seem reasonable to repeat these studies at a future date if kernel fissuring is again an issue.

The $95 \%$ confidences were calculated on the means with the beta-inverse function, which is known to be inaccurate when the "success" count is less than five and strongly influenced by the population size. Nonetheless, because most of the population sizes were similar, the confidence intervals on the means are useful for comparing one case to another.

Table 4. Kernel fissure-reduction study with the 2.5 -in. sintering furnace.

\begin{tabular}{|c|c|c|c|c|c|c|c|c|}
\hline \multicolumn{5}{|c|}{ 21/2-in. Furnace Tests } & \multicolumn{4}{|c|}{ Fissure Defect Fraction } \\
\hline $\begin{array}{c}\text { Sintered } \\
\text { Batch }\end{array}$ & $\begin{array}{c}\text { Green } \\
\text { Kernel } \\
\text { Batch }\end{array}$ & Washing & Drying & Calcining & $\begin{array}{l}\text { Kernel } \\
\text { Count }\end{array}$ & $\begin{array}{c}\text { Fissured } \\
\text { Kernel } \\
\text { Count }\end{array}$ & $\begin{array}{c}\text { Fissure } \\
\text { Fraction }\end{array}$ & $\begin{array}{l}95 \% \\
\text { Conf. } \\
\text { UCL }\end{array}$ \\
\hline 59226 & 29133 & Baseline & Baseline & Baseline & 2232 & 1 & $0.45 \mathrm{E}-3$ & $2.1 \mathrm{E}-3$ \\
\hline 59230 & 29137 & Baseline & Baseline & Baseline & 542 & 2 & $3.7 \mathrm{E}-3$ & $11.6 \mathrm{E}-3$ \\
\hline 59232 & $23139 \mathrm{~A}$ & Baseline & Baseline & Baseline & 502 & 3 & $6.0 \mathrm{E}-3$ & $15.4 \mathrm{E}-3$ \\
\hline 59228 & 29135 & $\begin{array}{c}\text { Extended } \\
\text { Wash }\end{array}$ & Baseline & Baseline & 1034 & 0 & 0 & $2.9 \mathrm{E}-3$ \\
\hline 59227 & 29134 & Baseline & Cool Air & Baseline & 2160 & 3 & $1.4 \mathrm{E}-3$ & $3.6 \mathrm{E}-3$ \\
\hline 59231 & 29138 & Baseline & Cool Air & Baseline & 587 & 11 & $18.7 \mathrm{E}-3$ & $30.8 \mathrm{E}-3$ \\
\hline 59229 & 29136 & Baseline & Baseline & High Flow & 601 & 0 & 0 & $5.0 \mathrm{E}-3$ \\
\hline 59233 & $29139 \mathrm{~S}$ & Tween 20 & Baseline & High Flow & 537 & 0 & 0 & $5.6 \mathrm{E}-3$ \\
\hline 59234 & - & Tween 20 & Baseline & Baseline & 535 & 3 & $5.6 \mathrm{E}-3$ & $14.4 \mathrm{E}-3$ \\
\hline
\end{tabular}

These data were presented to the Technical Coordinating Team (TCT) and AGR program management for their consideration. Without indisputable evidence that any modification was effective in reducing kernel fissures, management decided to follow the TCT recommendation to proceed with fabricating kernel lots J52R-16-69317 and J52R-16-69318 using baseline conditions. 


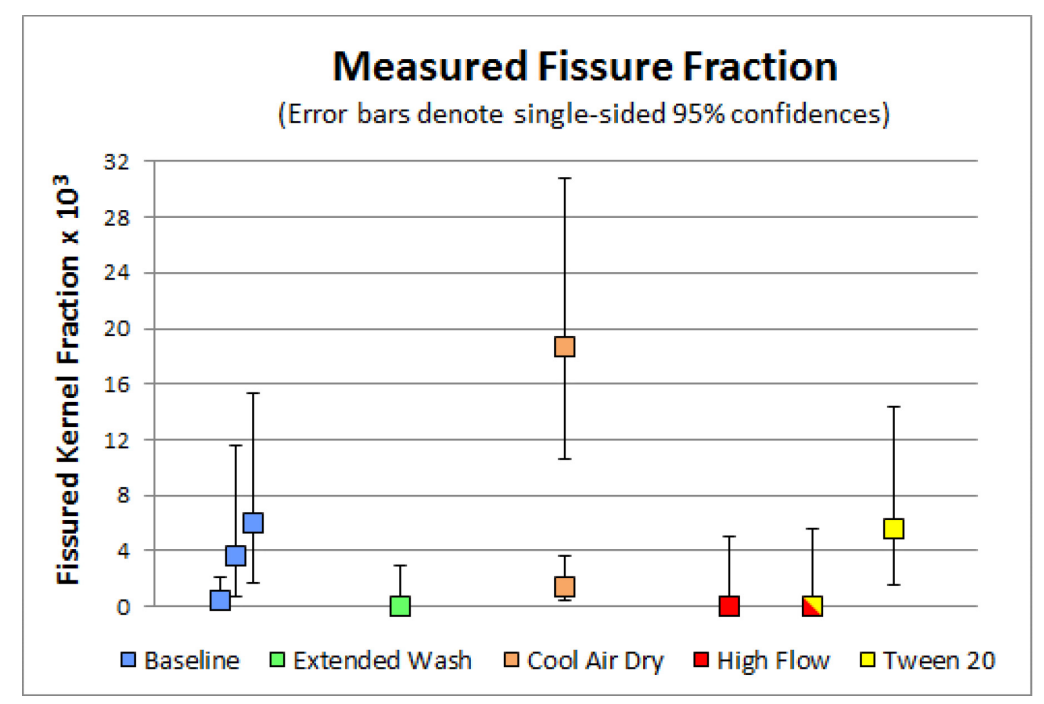

Figure 8. Kernel fissure fractions from the reduction study.

\subsection{Certified Kernel Lots J52R-16-69317 and 69318}

Fabrication of new LEUCO kernels proceeded quickly once the decision was made to exclude the certified kernel lot J52R-16-69316 from AGR-5/6/7 fuel fabrication. To ensure that enough kernels would be available for the fissure fraction-reduction study and AGR-5/6/7, excess ADUN was prepared. Several batches of kernels were fabricated until a sufficient quantity was on hand to compose another certified kernel lot, Lot J52R-16-69317. Individual kernel batches were mounted and sectioned to get an estimate of the fissure fraction. While characterizing the batches for this kernel lot, kernel fabrication continued with the remaining ADUN for a backup kernel lot, Lot J52R-16-69318.

\subsubsection{Kernel-batch Characterization Data}

Batch characterization data are shown in Table 5 for kernel batches fabricated and composited for the two kernel lots characterized for the AGR-5/6/7 experiments. The composition and dimensional data are very consistent from batch to batch. Kernel Batches 59533 and 59534 were not included in the J52R-16-69318 kernel lot because their measured countable fissure fractions were around 3\%.

Table 5. UCO kernel batch characterization data.

\begin{tabular}{|c|c|c|c|c|c|c|c|c|c|}
\hline \multicolumn{10}{|c|}{ Kernel Batches Used in Lot J52R-16-69317 (Phase I) } \\
\hline $\begin{array}{l}\text { Batch } \\
\text { ID }\end{array}$ & $\begin{array}{c}\text { Diameter } \\
(\mu \mathrm{m})\end{array}$ & $\begin{array}{c}\text { Density } \\
\text { (g/cc) }\end{array}$ & $\begin{array}{c}\text { Enrichment } \\
(w t \%)\end{array}$ & $\begin{array}{c}\mathrm{U} \\
(w t \%)\end{array}$ & C:U & O:U & $\begin{array}{c}\text { Fissure } \\
\text { Fraction }(95 \%) \\
\end{array}$ & $\begin{array}{l}\text { Aspect } \\
\text { Ratio }\end{array}$ & $\begin{array}{c}\text { Mass } \\
(\mathrm{g})\end{array}$ \\
\hline 59526 & 430.8 & 10.99 & 15.49 & 89.36 & 0.37 & 1.45 & $0.9 \%(1.8 \%)$ & 1.012 & 2,959 \\
\hline 59527 & 433.5 & 10.97 & 15.53 & 89.39 & 0.37 & 1.45 & $1.2 \%(2.3 \%)$ & 1.014 & 2,627 \\
\hline 59528 & 429.1 & 10.94 & 15.43 & 89.52 & 0.41 & 1.38 & $0.2 \%(0.8 \%)$ & 1.012 & 2,980 \\
\hline 59529 & 419.9 & 10.96 & 15.50 & 89.53 & 0.37 & 1.42 & $0.2 \%(0.8 \%)$ & 1.012 & 2,942 \\
\hline 59530 & 424.2 & 11.05 & 15.57 & 89.51 & 0.37 & 1.44 & $0.6 \%(1.1 \%)$ & 1.013 & 2,750 \\
\hline 59531 & 421.5 & 11.01 & 15.57 & 89.56 & 0.33 & 1.48 & $0.0 \%(0.5 \%)$ & 1.010 & 3,051 \\
\hline & & & & & & & & Total & 17,000 \\
\hline \multicolumn{10}{|c|}{ Kernel Batches Used in Lot J52R-16-69318 (Phase II) } \\
\hline $\begin{array}{l}\text { Batch } \\
\text { ID }\end{array}$ & $\begin{array}{c}\text { Diameter } \\
(\mu \mathrm{m})\end{array}$ & $\begin{array}{c}\text { Density } \\
(\mathrm{g} / \mathrm{cc})\end{array}$ & $\begin{array}{c}\text { Enrichment } \\
(\mathbf{w t} \%)\end{array}$ & $\begin{array}{c}\mathrm{U} \\
(\mathrm{wt} \%)\end{array}$ & $\mathrm{C}: \mathrm{U}$ & O:U & $\begin{array}{c}\text { Fissure } \\
\text { Fraction }(95 \%) \\
\end{array}$ & $\begin{array}{c}\text { Aspect } \\
\text { Ratio }\end{array}$ & $\begin{array}{c}\text { Mass } \\
\text { (g) }\end{array}$ \\
\hline 59532 & 422.2 & 11.06 & 15.57 & 89.46 & 0.30 & 1.52 & $0.8 \%(1.8 \%)$ & 1.012 & 2,467 \\
\hline 59535 & 421.3 & 11.16 & 15.46 & 89.73 & 0.35 & 1.43 & $1.0 \%(2.0 \%)$ & 1.012 & 2,153 \\
\hline \multicolumn{10}{|c|}{ Total } \\
\hline
\end{tabular}




\subsubsection{Kernel-lot Certification Data}

Characterization properties for the kernel lots, fuel specifications, and measured property data are given in Table 6. All properties were compliant with the fuel specification at the specified confidence levels with the exception of the impurities in Lot J52R-16-69318. Some of the impurities failed to show compliance at the $95 \%$ confidence level because the sample set was too small. All of the results were reported as being below the statistical detection limit for the respective elements, so the upper limit at $95 \%$ confidence would be similar to that of Lot J52R-16-69317, if the same number of replicate analyses had been performed.

Table 6. AGR-5/6/7 certified UCO kernel lot characterization data.

\begin{tabular}{|c|c|c|c|}
\hline Kernel Lot Properties & Specification & J52R-16-69317 a & J52R-16-69318 a, b \\
\hline Diameter $(\mu \mathrm{m})$ & $\begin{aligned} & 425 \pm 10 \\
& \leq 1 \%<375 \\
& \leq 1 \%>475 \\
&\end{aligned}$ & $\begin{array}{c}425.78 \pm 10.42 \\
1 \%<397.81 \\
1 \%>453.74 \\
\end{array}$ & $\begin{array}{c}422.69 \pm 5.52 \\
1 \%<407.88 \\
1 \%>437.50 \\
\end{array}$ \\
\hline Envelope density $\left(\mathrm{g} / \mathrm{cm}^{3}\right)$ & $\geq 10.4$ & $\begin{array}{c}11.048 \pm 0.044 \\
\mathrm{LL} \geq 11.018\end{array}$ & $\begin{array}{c}11.075 \pm 0.035 \\
\mathrm{LL} \geq 10.917\end{array}$ \\
\hline Uranium fraction (g U/g UCO) & $\geq 0.885$ & $\begin{array}{c}0.8968 \pm 0.0004 \\
L L \geq 0.8965\end{array}$ & $\begin{array}{c}0.8965 \pm 0.00014 \\
L L \geq 0.8958\end{array}$ \\
\hline${ }^{235} \mathrm{U}$ enrichment ( $\left.\mathrm{g}{ }^{235} \mathrm{U} / \mathrm{g} \mathrm{U}\right)$ & $0.155 \pm 0.001$ & $\begin{array}{c}0.15477 \pm 0.00013 \\
\mathrm{LL} \geq 0.1546 \\
\mathrm{UL} \leq 0.1549\end{array}$ & $\begin{array}{c}0.15433 \pm 0.00099 \\
\mathrm{LL} \geq 0.1534 \\
\mathrm{UL} \leq 0.1552\end{array}$ \\
\hline $\mathrm{C}: \mathrm{U}$ (atomic ratio) & $0.40 \pm 0.10$ & $0.370 \pm 0.000$ & $0.330 \pm 0.000$ \\
\hline $\mathrm{O}: \mathrm{U}$ (atomic ratio) & $1.50 \pm 0.20$ & $\begin{array}{c}1.441 \pm 0.0035 \\
\mathrm{LL} \geq 1.438 \\
\mathrm{UL} \leq 1.444\end{array}$ & $\begin{array}{c}1.470 \pm 0.014 \\
\mathrm{LL} \geq 1.343 \\
\mathrm{UL} \leq 1.597\end{array}$ \\
\hline$(\mathrm{C}+\mathrm{O}) / \mathrm{U}$ (atomic ratio) & $\leq 2.0$ & $\begin{array}{c}1.811 \pm 0.0035 \\
\mathrm{UL} \leq 1.814\end{array}$ & $\begin{array}{c}1.795 \pm 0.007 \\
\mathrm{UL} \leq 1.827\end{array}$ \\
\hline $\begin{array}{r}\text { Individual impurities (ppmw): } \\
\qquad \mathrm{Cl}, \mathrm{Ca}, \& \mathrm{Fe} \\
\mathrm{Al}, \mathrm{Co}, \mathrm{Cr}, \mathrm{Cu}, \mathrm{Mn}, \mathrm{Na}, \mathrm{Ni}, \& \mathrm{Zn} \\
\mathrm{Li} \& \mathrm{~V}\end{array}$ & $\leq 100$ each & $\begin{array}{c}<25 ; \mathrm{UL}<30.9 \\
\leq 10.3 ; \mathrm{UL} \leq 13.7 \\
<5 ; \mathrm{UL}<6.2\end{array}$ & $\begin{array}{l}<25 ; \mathrm{UL}<124^{\mathrm{c}} \\
<10 ; \mathrm{UL}<49.6 \\
<5 ; \mathrm{UL}<24.8\end{array}$ \\
\hline Process impurities (ppmw): & $\leq 1,500$ each & $\begin{array}{c}<25 ; \mathrm{UL}<30.9 \\
246.6 ; \mathrm{UL}<255.9\end{array}$ & $\begin{array}{c}<25 ; \mathrm{UL}<124 \\
241.5 ; \mathrm{UL}<301.5\end{array}$ \\
\hline Aspect ratio & $\leq 10 \% \geq 1.05$ & $10 \% \geq 1.020$ & $10 \% \geq 1.023$ \\
\hline Countable Fissure Fractions ${ }^{d}$ & - & $\begin{array}{c}0.59 \% \\
\mathrm{LL} \geq 0.36 \% \\
\mathrm{UL} \leq 0.93 \%\end{array}$ & $\begin{array}{c}1.02 \% \\
\mathrm{LL} \geq 0.70 \% \\
\mathrm{UL} \leq 1.43 \%\end{array}$ \\
\hline \multicolumn{4}{|c|}{$\begin{array}{l}\text { a. All variable property upper limits (UL), lower limits (LL), and dispersion tests }(\text { e.g., } 1 \%<\ldots \text { ) are at } 95 \% \text { confidence } \\
\text { levels. } \\
\text { b. Failures to conform to the fuel specifications at the designated confidence level (generally } 95 \%) \text { are denoted in red. } \\
\text { c. The averages of all impurities were below detection levels }(25 \mathrm{ppmw} \text { or less). Few replicate analyses resulted in a large } \\
\text { estimated standard-deviation and a large upper-limit estimate for } \mathrm{Ca}, \mathrm{Cl} \text {, and } \mathrm{Fe} \text {. All others were } \mathrm{UL}<50 \mathrm{ppmw} \text { at } 95 \% \\
\text { confidence. } \\
\text { d. Countable fissures are defined in Section 2.2.2.3. }\end{array}$} \\
\hline
\end{tabular}




\section{TRISO PARTICLES \\ 3.1 TRISO Coating Process Enhancements}

Several upgrades and changes were made to the BWXT facility to enhance TRISO coating-process functionality and reliability and eliminate potential sources of both layer variability and particle damage. The mass of TRISO particles charged to the coater for each run was also increased to improve productivity. The modified and upgraded equipment/systems include the

- Methyl trichlorosilane (MTS) evaporator

- Off-gas filter bank

- Acetylene gas pad

- Coating-furnace head and hot sampler

- Coating-furnace gas-distributor nozzle

- Coating-furnace retort bottom (a.k.a. "chalice") profile

- Coater TRISO-particle unloading system

- Coater temperature measurement.

The old MTS evaporator was a pot with an inverted conical insert to create an annular pool of MTS, with a surface area that varied with the pool depth. Any mismatch in the MTS liquid feed and the MTS vapor-discharge rate would result in changes to the MTS level and the exposed surface area of the annular MTS pool. A hydrogen sweep gas carried MTS vapors from the pot to the coating furnace. Variations in the MTS vapor-discharge rate resulted from pool-temperature cooling (enthalpy of vaporization) and pool depth, which also caused unacceptable variability in the instantaneous MTS vapor delivery rate to the coating furnace and a high batch-to-batch variability in the mass and thickness of the deposited silicon carbide layer.

The MTS evaporator pot was replaced with a Brooks TurboVaporizer. With the TurboVaporizer, the MTS is sprayed into a heated vessel, which is filled with random packing, to achieve total vaporization of the MTS without any accumulation of liquid MTS in the vessel. The SiC deposition rate was controlled only by the MTS feed rate, and this provided the needed uniformity in deposition rates and layer thicknesses. BWXT still monitored the mass of MTS transferred to the TurboVaporizer during the layer deposition and halted the transfer after a pre-calculated mass had been transferred.

The early off-gas filter bank consisted of two parallel pairs of serial filters. The filter bank was employed during $\mathrm{SiC}$ deposition to catch the particulates from the coating furnace. A cake of particulates would build on the filter medium and increase back pressure until the selector valve was manually switched to the other filter pair. The building back pressure and sudden drop in back pressure when filter selection was changed affected bed fluidization, and there was concern that it might be associated with a discontinuity in the $\mathrm{SiC}$ microstructure near mid-radius of the SiC layer and/or a "pearl necklace" of micro-pores along an arc near the same radius within the SiC (Figure 9). The

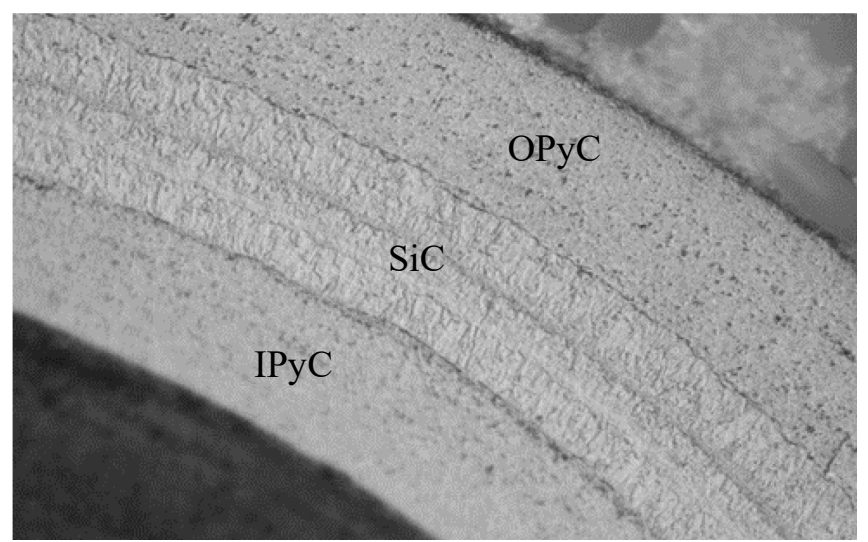

Figure 9. Polished and etched cross section of a TRISO particle showing a mid-radius $\mathrm{SiC}$ layer discontinuity in the crystalline microstructure. 
filter bank was replaced with one having multiple filters in parallel, such that the back pressure generally remained acceptable throughout the entire $\mathrm{SiC}$ deposition. The redesign of the filter bank resulted in improvements in the operational surety and uniformity of the $\mathrm{SiC}$ microstructure.

The acetylene gas pad was replaced with a larger pad and several additional acetylene tanks that were manifolded together so that the entire acetylene flow was not coming from a single tank and that switching of tanks could occur with little disruption in the gas flow. This reduced the likelihood of entraining higher concentrations of acetone from nearly depleted tanks, which could affect the chemistry of pyrocarbon formation during buffer deposition.

The top head of the coating furnace was replaced with a modified head that enabled larger grabsample stations to be installed for "hot" sampling of the bed. This enabled samples to be drawn following deposition of the buffer layer and following the IPyC layer for each coating run. Thus, density data became available for both of these internal layers on every coating batch, whereas only one or the other could be sampled previously.

Following AGR-2 TRISO-particle coating, development efforts shifted to improving the capacity of the coating furnace. The mass of kernels charged to the coating furnace was increased from $1.3 \mathrm{~kg}$ of UCO kernels to $2.0 \mathrm{~kg}$. On several coating batches, using unenriched UCO kernels, a curious dimpled pattern was observed in the $\mathrm{SiC}$ mirror that deposited on the nozzle (Figure 10). The pattern is consistent with a static bed surrounding the nozzle, and the pitch of the dimples suggests uncoated or minimally coated kernels. In one instance, a clod of kernels embedded in a pyrocarbon matrix was found in the coater after the bed had been removed. One face of the clod appeared to have conformed to the retort "chalice" wall. This confirmed that the bed was stagnating near the coater wall.

The chalice was redesigned to follow a catenary curve, making it narrower at the bottom and decreasing the effective included angle at the interface with the gas-distributor nozzle (Figure 11). Furthermore the diameter of the distributor nozzle

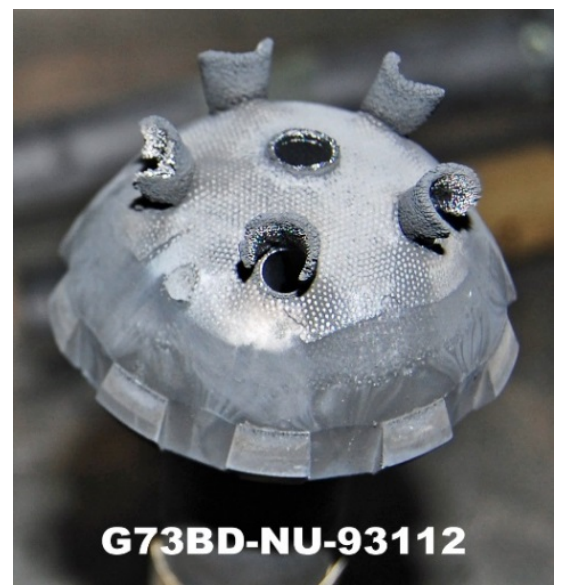

Figure 10. Former gas-distributor nozzle with a dimple pattern in the $\mathrm{SiC}$ accretions. was decreased from 2 to 1.5 in. (Figure 12). A serrated flange below the dome of the distributor nozzle limits the contact area with the bottom of the chalice to reduce conductive heat transfer to the nozzle while also forming an annular orifice between the chalice and nozzle through which inert gases were passed to cool the nozzle. The inert gases dilute reactive gases near the exposed surface of the nozzle and fluidize the bed at the bottom of the chalice. Following these modifications, no further evidence of bed stagnation has been observed. 

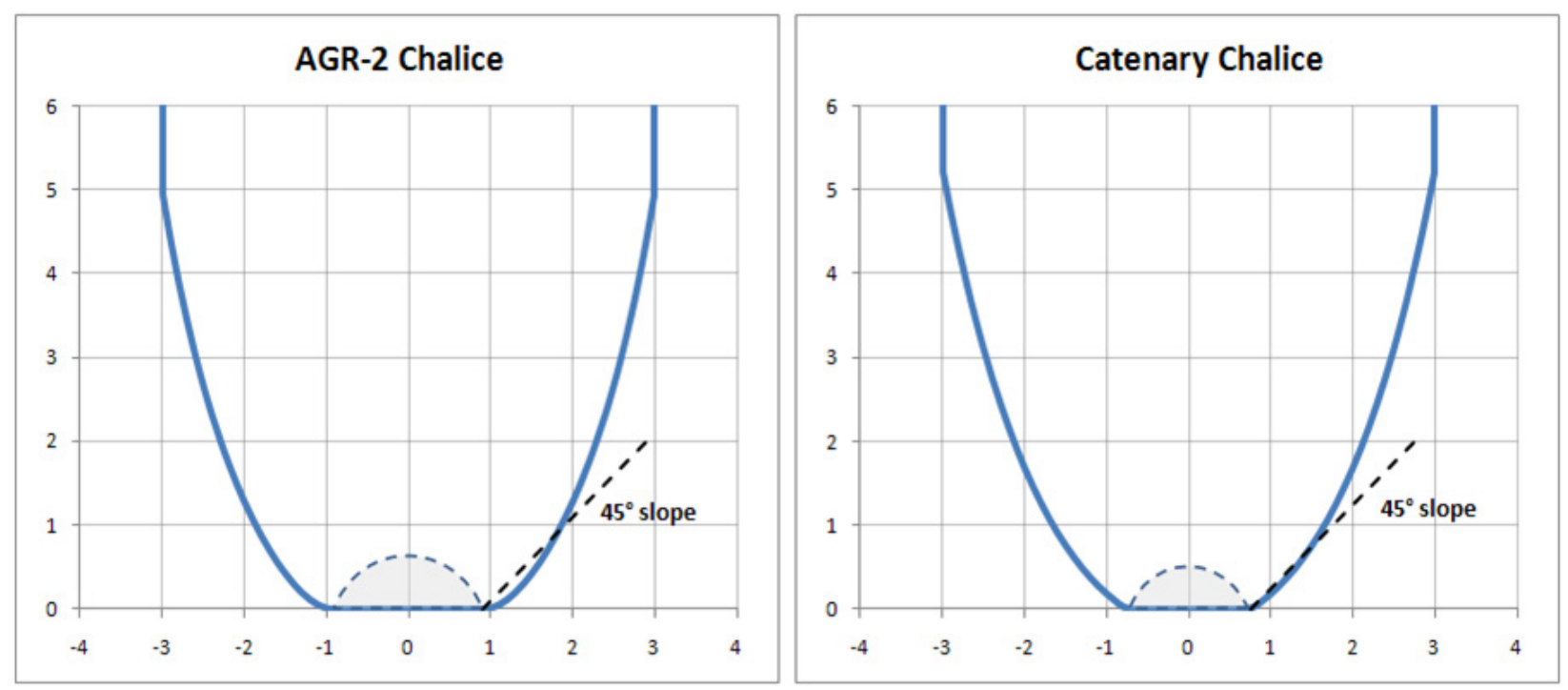

Figure 11. Chalice profiles for AGR-2 and subsequent coating runs.

There was concern that the vacuum system used to unload the TRISO coated particles from the coating furnace could be cracking and breaking the coatings. The system employed a metal wand with a rubber tip banded to the exterior with a hose clamp. Not only did the band contact the particle bed, but the particles could strike the lip of the metal tube as they were drawn into the inlet. The journey of the particle included passing through a few bulkhead compression fittings, elbows, and into a simple BWXT-built cyclonic separator with a nearly-tangential inlet. These were replaced with a soft wand, stiffened by an exterior metal tube (no banding required) that passed through bulkhead fittings (no contact with the fitting internals as was the case before), and followed long-radius bends in the soft tubing to a commercially designed and fabricated cyclonic separator. Although the revised unloading system was gentler on the particles, no dramatic decreases in the exposed kernel defect fraction were observed.

The coating properties are strongly affected by the layer deposition temperatures. Early development work used a long Type $\mathrm{C}$ thermocouple (position TC10, Figure 13) inserted through the top head of the furnace to sense temperature. Each time the head was removed to vacuum out the product, the position of TC10 could vary. It was also possible that the thermocouple was "flagging" in the gas stream due its length. Inconsistent positioning and movement of the thermocouple yielded inconsistent results in the layer properties

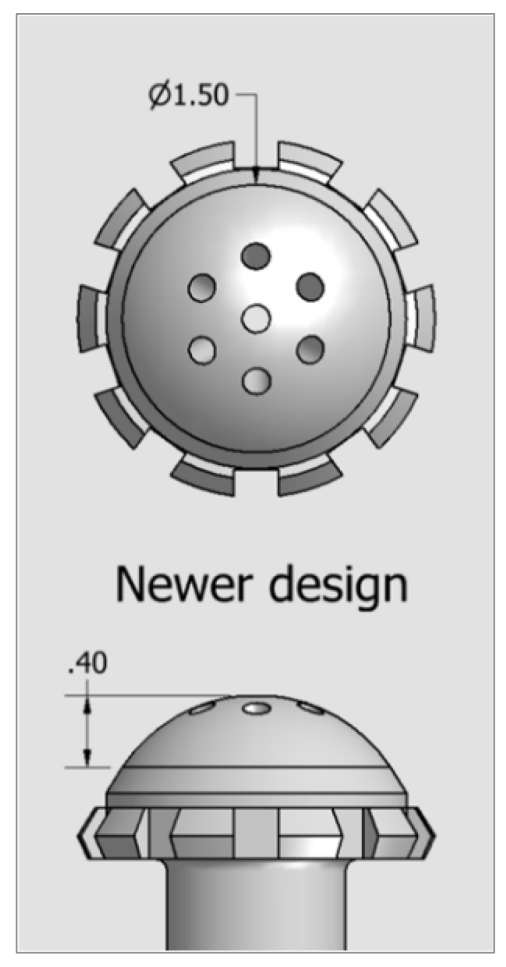

Figure 12. Redesigned gasdistributor nozzle. during coating development. Thermocouple TC7, which was used for over-temperature protection, was also used during fabrication of AGR-2 TRISO particles to control process temperature. Being external to the coating retort and at an elevation well above the bed, it could not give an accurate measure of the true bed temperature. Changes to gas-flow rates and bed-charge masses required adjustments to the temperature setpoints to achieve the desired layer properties. Optical pyrometry was also attempted at a position indicated in Figure 13 (Opt Pyr), but the "view" through the gaps in the heater shell did not allow for accurate measurement of the retort spot temperature. Ultimately, TC4 was used with success to control bed temperature. Being lower than the bed level during most of the 
time when depositions were taking place, TC4 was more responsive to changes in gas flow and charge masses than TC7. All of the thermocouples were Type C. To improve consistency in the layer properties, new thermocouples were heat treated to "burn them in" to reduce early drift at high temperatures and TCs were compared to a reference-standard thermocouple to ensure that they were reading within tolerances for the coating furnace.

\subsection{TRISO Particle Fabrication}

Arguments for and against inclusion of process specifications for fuel fabrication were given by various parties. One argument for process specifications is that the program has not yet shown that the product specifications are sufficient to ensure satisfactory performance of the fuel under normal reactor operation and credible accident scenarios. The specifications given in Table 7 are based on the process parameters that yielded the desired product characteristics when the BWXT-NOG 6-in. TRISO coating furnace was used. As such, the temperatures are dependent on the coater design and the nature and placement of temperature instruments.

The $\mathrm{OPyC}$ coating rate can be difficult to maintain, without increasing the coating-gas fraction due to the backpressure on inlet gases resulting from accretions of carbon and silicon carbide surrounding the gas distributor nozzle orifices. Acetylene flow could not always be maintained as back pressure increased because acetylene supply pressure is limited to $15 \mathrm{psig}$, and the flow controller had a minimum required pressure drop to control gas flow. To compensate for the high back pressure, the flow rates of all gases were reduced so that the coating gas fraction and the acetylene to propylene ratio could be maintained while reducing back pressure. This action did not impact the OPyC layer properties other than the thickness, as seen in Table 8, which could have been corrected by extending the coating duration by approximately 2 minutes. BWXT-NOG was given the operational flexibility to adjust the gas flow rates and coating times as needed to sustain the desired acetylene fraction and target the desired OPyC thickness. Lag time between fabrication and obtaining measurements of the OPyC layer thicknesses prevented the coating time from being accurately extended when needed.

Table 7. TRISO particle coating batch process parameters.

\begin{tabular}{|r|c|c|c|c|c|}
\hline \multicolumn{1}{|c|}{ Process Parameter } & Specification & $\begin{array}{c}\text { J52O-16- } \\
\text { 93165B }\end{array}$ & $\begin{array}{c}\text { J52O-16- } \\
\text { 93168B }\end{array}$ & $\begin{array}{c}\text { J52O-16- } \\
\text { 93169B }\end{array}$ & $\begin{array}{c}\text { J52O-16- } \\
\text { 93170B }\end{array}$ \\
\hline $\begin{array}{c}\text { Buffer } \\
\text { Mean temperature }\left({ }^{\circ} \mathrm{C}\right)\end{array}$ & $1420 \pm 20$ & $1421(1439)$ & $1420(1441)$ & $1420(1437)$ & $1421(1436)$ \\
\hline Coating gas fraction & $0.60 \pm 0.06$ & 0.598 & 0.599 & 0.598 & 0.599 \\
\hline Coating rate $(\mu \mathrm{m} / \mathrm{min})$ & $\sim 20$ & 18.9 & 17.5 & 17.9 & 18.5 \\
\hline Coating duration $(\mathrm{min})$ & - & 5.5 & 5.5 & 5.5 & 5.5 \\
\hline Total gas flow $(\mathrm{slpm})$ & - & 241.9 & 229.3 & 228.8 & 229.3 \\
\hline
\end{tabular}


Table 7. (continued).

\begin{tabular}{|c|c|c|c|c|c|}
\hline Process Parameter & Specification & $\begin{array}{c}\text { J52O-16- } \\
93165 B \\
\end{array}$ & $\begin{array}{c}\text { J52O-16- } \\
93168 B \\
\end{array}$ & $\begin{array}{c}\text { J52O-16- } \\
\text { 93169B } \\
\end{array}$ & $\begin{array}{c}\text { J52O-16- } \\
\text { 93170B } \\
\end{array}$ \\
\hline \multicolumn{6}{|l|}{ IPyC } \\
\hline Mean temperature $\left({ }^{\circ} \mathrm{C}\right)$ & $1310 \pm 10$ & 1310 & 1309 & 1309 & 1309 \\
\hline Coating gas fraction & $0.30 \pm 0.03$ & 0.297 & 0.297 & 0.297 & 0.297 \\
\hline Acetylene fraction & $0.54 \pm 0.02$ & 0.540 & 0.538 & 0.538 & 0.538 \\
\hline Coating rate $(\mu \mathrm{m} / \mathrm{min})$ & $\sim 3.0$ & 3.1 & 3.0 & 3.0 & 2.9 \\
\hline Coating duration (min) & - & 13.25 & 13.0 & 13.0 & 13.0 \\
\hline Total gas flow (slpm) & - & 266.6 & 256.4 & 256.5 & 256.5 \\
\hline \multicolumn{6}{|l|}{$\mathrm{SiC}$} \\
\hline Mean temperature $\left({ }^{\circ} \mathrm{C}\right)$ & $1565 \pm 30$ & 1564 & 1565 & 1565 & 1565 \\
\hline Coating gas fraction & $0.030 \pm 0.005$ & 0.0288 & 0.0297 & 0.0299 & 0.030 \\
\hline Argon : hydrogen ratio & $30: 70$ & $30: 70$ & $30: 70$ & $30: 70$ & $30: 70$ \\
\hline Coating rate $(\mu \mathrm{m} / \mathrm{min})$ & $\sim 0.38$ & 0.35 & 0.38 & 0.38 & 0.37 \\
\hline Coating duration (min) & - & 105.9 & 93.9 & 95.1 & 97.6 \\
\hline Total gas flow (slpm) & - & 201.8 & 200.4 & 200.6 & 200.5 \\
\hline \multicolumn{6}{|l|}{ OPyC } \\
\hline Mean temperature $\left({ }^{\circ} \mathrm{C}\right)$ & $1350 \pm 15$ & 1352 & 1350 & 1350 & 1350 \\
\hline Coating gas fraction & $0.32 \pm 0.03$ & 0.316 & 0.317 & 0.317 & 0.317 \\
\hline Acetylene fraction & $0.54 \pm 0.02$ & 0.538 & 0.539 & 0.538 & 0.538 \\
\hline Coating rate $(\mu \mathrm{m} / \mathrm{min})^{\mathrm{b}}$ & $\sim 2.7$ & 2.0 & 2.4 & 2.2 & 2.2 \\
\hline Coating duration (min) & - & 15.0 & 16.0 & 16.0 & 16.0 \\
\hline Total gas flow (slpm) ${ }^{b}$ & - & 185.7 & 234.5 & 234.5 & 234.4 \\
\hline \multicolumn{6}{|c|}{$\begin{array}{l}\text { a. Buffer-temperature specification is on the mean temperature } 1 \text { minute before starting flow of acetylene because of the } \\
\text { exothermicity of acetylene decomposition and the somewhat stochastic nature of the mean coating temperature (shown in } \\
\text { parentheses). } \\
\text { b. Total gas flow during OPyC deposition can be restricted by nozzle accretions and the back pressure on the acetylene line; } \\
\text { necessitating a reduction in total gas flow to sustain a controllable acetylene flow. }\end{array}$} \\
\hline
\end{tabular}

TRISO batch and lot characterization data are presented in Table 8. Sample sizes used to characterize the individual batches were not required to meet the criteria of the sampling plan for characterizing the composited lot, but provided adequate information for down-selecting batches for inclusion in the composited TRISO particle lot. ${ }^{5}$ Once the selected particle batches were blended, the composite was characterized in full conformance to the sampling plan guidelines on sample sizes.

The composited TRISO particle lot (J52R-16-98005) met all fuel specifications on the mean and for the dispersion except for the OPyC thickness (shown in red). The OPyC thickness was deficient in the mean and the lower limit of the mean, but not in the lower dispersion limit.

The IPyC defect fractions for two batches exceeded the fuel specification maximum at the 95\% confidence level. This is partially due to the limited size of the samples from the individual batches. Measurements taken for the composited lot used a significantly larger sample size, which decreased the uncertainty in the statistical calculation and yielded an estimate of the true defect fraction that passed the specification at $95 \%$ confidence. 
Pre-burn and post-burn leaches were performed to get an indication of the dispersed uranium fractions and exposed kernel fractions to ensure that only TRISO products with low defect fractions were used in subsequent fuel fabrication processes. These analyses were not required by the fuel specification at the particle level, but are specified for compact batches. From these preliminary results, it was understood that the compacts may fail the dispersed uranium specification, but were expected to pass the exposed kernel and defective silicon carbide specifications.

Three TRISO coated particle batches that were fabricated for possible inclusion in the certified TRISO lot for AGR-5/6/7 were excluded for not meeting various fuel specifications and are not shown in Table 8. TRISO batch J52O-16-93164 was excluded from the composited lot because it failed to meet minimum specifications for SiC and OPyC layer thicknesses. J52O-16-93166 TRISO particles were not included because of an excessively thick SiC layer thickness, although it did pass the OPyC thickness specification. Meeting the $\mathrm{SiC}$ thickness specifications is thought to be more important than the OPyC thickness. J52O-16-93167 was excluded because the coating batch was interrupted at the onset of SiC deposition and not completed. The letter ' $\mathrm{B}$ ' was appended to the batch numbers to indicate that the TRISO batches had been sieved twice to remove undersized and broken particles.

Table 8. TRISO particle batch and lot characteristics.

\begin{tabular}{|c|c|c|c|c|c|c|}
\hline $\begin{array}{c}\text { TRISO Particle } \\
\text { Property }\end{array}$ & Specification & $\begin{array}{l}\text { J52O-16- } \\
\text { 93165B } \\
\end{array}$ & $\begin{array}{l}\text { J52O-16- } \\
\text { 93168B }^{\text {a }}\end{array}$ & $\begin{array}{l}\text { J52O-16- } \\
\text { 93169B }^{\text {a }}\end{array}$ & $\begin{array}{l}\text { J520-16- } \\
\text { 93170B }^{\text {a }} \\
\end{array}$ & J52R-16-98005 a, b, d \\
\hline $\begin{array}{l}\text { Buffer thickness } \\
(\mu \mathrm{m})\end{array}$ & $\begin{array}{l}100 \pm 15 \\
\leq 1 \% \leq 58\end{array}$ & 104.5 & 96.6 & 98.7 & 101.5 & $\begin{array}{c}100.4 \pm 5.6 \\
\text { (range } 99.6-101.1 \text { ) } \\
1 \%<88.4\end{array}$ \\
\hline IPyC thickness $(\mu \mathrm{m})$ & $\begin{aligned} & 40 \pm 4 \\
\leq & 1 \% \leq 30 \\
\leq & 1 \% \geq 52\end{aligned}$ & 40.7 & 39.1 & 38.9 & 38.2 & $\begin{array}{c}39.24 \pm 1.26 \\
\text { (range } 39.06-39.41 \text { ) } \\
1 \%<36.53 \\
1 \%>41.94\end{array}$ \\
\hline SiC thickness $(\mu \mathrm{m})$ & $\begin{array}{r}35 \pm 3 \\
\leq 1 \% \quad 28 \\
\end{array}$ & 36.6 & 35.7 & 35.8 & 36.5 & $\begin{array}{c}36.15 \pm 0.65 \\
(\text { range } 36.06-36.24) \\
1 \%<34.75 \\
\end{array}$ \\
\hline $\begin{array}{l}\text { OPyC thickness } \\
(\mu \mathrm{m})\end{array}$ & $\begin{array}{c}40 \pm 4 \\
\leq 1 \% \leq 20\end{array}$ & 30.3 & 38.5 & 36.0 & 35.6 & $\begin{array}{c}35.03 \pm 1.99 \\
\text { (range } 34.75-35.31) \\
1 \%<30.76\end{array}$ \\
\hline $\begin{array}{l}\text { Buffer density } \\
\left(\mathrm{g} / \mathrm{cm}^{3}\right)\end{array}$ & $1.05 \pm 0.10$ & 1.04 & 1.05 & 1.00 & 1.03 & $\begin{array}{c}1.031 \pm 0.022 \\
\text { (range } 0.996-1.065 \text { ) }\end{array}$ \\
\hline $\begin{array}{l}\text { IPyC density } \\
\left(\mathrm{g} / \mathrm{cm}^{3}\right)\end{array}$ & $\begin{array}{l}1.90 \pm 0.05 \\
\leq 1 \% \leq 1.80 \\
\leq 1 \% \geq 2.00\end{array}$ & 1.895 & 1.899 & 1.898 & 1.897 & $\begin{array}{c}1.897 \pm 0.099 \\
\text { (range } 1.896-1.898) \\
1 \%<1.876 \\
1 \%>1.918 \\
\end{array}$ \\
\hline $\mathrm{SiC}$ density $\left(\mathrm{g} / \mathrm{cm}^{3}\right)$ & $\begin{array}{r}\geq 3.19 \\
\leq 1 \% \leq 3.17 \\
\end{array}$ & 3.195 & 3.194 & 3.196 & 3.194 & $\begin{array}{c}3.195 \pm 0.002 \\
\text { (range } \geq 3.1945) \\
1 \%<3.1913 \\
\end{array}$ \\
\hline $\begin{array}{l}\text { OPyC density } \\
\left(\mathrm{g} / \mathrm{cm}^{3}\right)\end{array}$ & $\begin{array}{l}1.90 \pm 0.05 \\
\leq 1 \% \leq 1.80 \\
\leq 1 \% \geq 2.00\end{array}$ & 1.894 & 1.901 & 1.900 & 1.895 & $\begin{array}{c}1.897 \pm 0.004 \\
\text { (range } 1.897-1.898 \text { ) } \\
1 \%<1.876 \\
1 \%>1.918\end{array}$ \\
\hline
\end{tabular}


Table 8. (continued).

\begin{tabular}{|c|c|c|c|c|c|c|}
\hline $\begin{array}{c}\text { TRISO Particle } \\
\text { Property }\end{array}$ & Specification & $\begin{array}{l}\text { J52O-16- } \\
\text { 93165B }^{\text {a }}\end{array}$ & $\begin{array}{l}\text { J52O-16- } \\
\text { 93168B }^{\text {a }} \\
\end{array}$ & $\begin{array}{l}\text { J52O-16- } \\
\text { 93169B } \\
\end{array}$ & $\begin{array}{l}\text { J52O-16- } \\
\text { 93170B }^{\text {a }}\end{array}$ & J52R-16-98005 a, b, d \\
\hline IPyC diattenuation $^{c}$ & $\begin{array}{r}\leq 0.0170 \\
\leq 1 \% \geq 0.0242 \\
\end{array}$ & 0.0144 & 0.0139 & 0.0151 & 0.0144 & $\begin{array}{c}0.0153 \pm 0.0010 \\
(\text { range } \leq 0.016) \\
1 \%>0.019\end{array}$ \\
\hline $\mathrm{OPyC}$ diattenuation ${ }^{\mathrm{c}}$ & $\begin{array}{r}\leq 0.0122 \\
\leq 1 \% \geq 0.0242 \\
\end{array}$ & 0.0095 & 0.0097 & 0.0103 & 0.0096 & $\begin{array}{c}0.0102 \pm 0.0006 \\
\text { (range } \leq 0.010) \\
1 \%>0.012\end{array}$ \\
\hline $\begin{array}{l}\mathrm{SiC} \text { aspect ratio } \\
\text { (faceting) }\end{array}$ & $\begin{array}{c}- \\
\leq 1 \% \geq 1.14 \\
\end{array}$ & 1.052 & 1.055 & 1.056 & 1.051 & $\begin{array}{c}1.053 \pm 0.009 \\
1 \%>1.0735 \\
\end{array}$ \\
\hline $\begin{array}{l}\text { Defective IPyC } \\
\text { coating fraction }^{\mathrm{c}}\end{array}$ & $\leq 1.0 \mathrm{E}-4$ & $<0.52 \mathrm{E}-4$ & $<2.21 \mathrm{E}-4$ & $<0.86 \mathrm{E}-4$ & $<1.21 \mathrm{E}-4$ & $<0.75 \mathrm{E}-4$ \\
\hline $\begin{array}{l}\text { Defective OPyC } \\
\text { defect fraction }\end{array}$ & $\leq 3.0 \mathrm{E}-4$ & $<1.7 \mathrm{E}-4$ & $<1.7 \mathrm{E}-4$ & $<1.7 \mathrm{E}-4$ & $<1.7 \mathrm{E}-4$ & $<0.86 \mathrm{E}-4$ \\
\hline Pre-burn, mean & - & $5.69 \mathrm{E}-5$ & $0.43 \mathrm{E}-5$ & $0.88 \mathrm{E}-5$ & $1.27 \mathrm{E}-5$ & $1.11 \mathrm{E}-5$ \\
\hline Post-burn, mean & - & $9.87 \mathrm{e}-5$ & $1.92 \mathrm{E}-5$ & $1.38 \mathrm{E}-5$ & $4.35 \mathrm{E}-5$ & $2.19 \mathrm{E}-5$ \\
\hline \multicolumn{2}{|l|}{ Masses $(\mathrm{kg})$} & 3.057 & 2.996 & 2748 & 2845 & 11.646 \\
\hline \multicolumn{7}{|c|}{$\begin{array}{l}\text { a. Failures to conform to the fuel specifications at the designated confidence level are shown in red } \\
\text { b. All variable property upper limits (UL), lower limits (LL), and dispersion tests (e.g., } 1 \%<\ldots \text { ) are at } 95 \% \text { confidence levels } \\
\text { c. Data from ORNL/TM-2017/036-R1 and ORNL/TM-2017/037-R0 } \\
\text { d. } 95 \% \text { confidence limits shown in parentheses for these variable properties: (LL }-\mathrm{UL}),(\geq \mathrm{LL}) \text {, or }(\leq \mathrm{UL})\end{array}$} \\
\hline
\end{tabular}

\section{FUEL COMPACTS}

\subsection{Resinated Graphite "Matrix" Powder}

AGR-1, -2, and -3/4 used a German A3-3 style resinated graphite powder from which the fuel compact matrix was formed. The A3-3 style resinated graphite powder was produced using a 20:80 blend of synthetic and purified natural flake graphite powders by weight. The powders were resinated with a viscous, alcohol-soluble resol phenolic resin containing formaldehyde as a hardening agent. Shelf life of the resin was limited and required refrigeration to slow polymerization and crosslinking reactions.

Production of the resinated graphite included the addition of a solvent (e.g., methanol) to the resin to reduce the resin viscosity and wet the graphite powders. The powders and solvated resin were kneaded into a dough, granulated, air dried, and ground to a powder in processes that took a few days to complete. The resin composed $20 \mathrm{wt} \%$ of the final product.

The resinated graphite powder for the AGR-5/6/7 experiment was similar to the German A3-27 formulation, but used a novolac phenolic resin flake, which was partially cross-linked instead of phenol. The novolac resin (Durite SD-1708) has no integral hardening agent and a much longer shelf life than a resol resin. The graphite blend was a 20:80 blend of synthetic (SGL KRB2000) and purified natural flake (Asbury 3482) graphites. The resinated graphite powder was produced in a two-step milling process. The novolac resin was co-milled with HMTA, and the resultant powder was subsequently blended and co-milled with the graphite powders. The HMTA serves as the hardener/curing agent for the novolac resin. Both milling operations were performed in a jet mill (Figure 14) by Jet Pulverizer Co., of Moorestown, NJ (Appendix A). The resulting powder had a mean particle diameter of less than $9 \mu \mathrm{m}$. The weight fractions were $80 \mathrm{wt} \%$ graphite, $19 \mathrm{wt} \%$ resin, and $1 \mathrm{wt} \%$ hardener. 


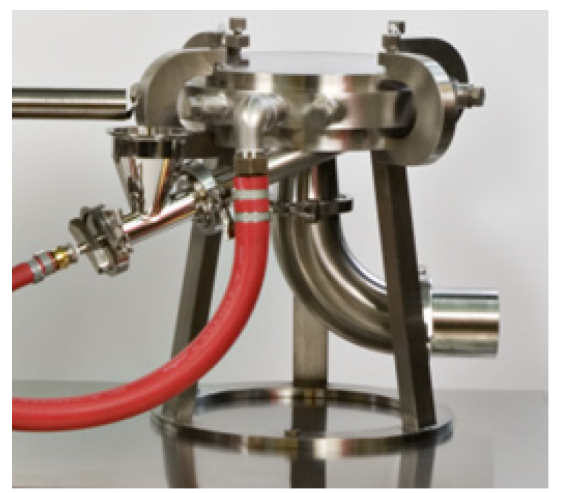

Figure 14. Jet mill.

The jet milling operation was selected because of the more-limited contact between the mill internals and the powder particles, which reduces the probability of chemical contamination, and because of the speed and efficiency with which the milling operation takes place. Additional considerations are that the process does not involve the use of flammable solvents (i.e., methanol) and lends itself well to custom fabrication by a third party.

Jet milling did reduce the final mean particle size below the $15 \mu \mathrm{m}$ target, but the fine particle size does not appear to have adversely affected the matrix performance during compact forming and thermal treatment.

\subsection{Overcoating of TRISO Particles}

Early AGR experiments using the A3-3 formulation required the use of a methanol spritz to soften the resin and give it sufficient "tack" while overcoating TRISO particles with the resinated graphite powder in a tilted rotating-drum overcoater. Periodic additions of powder were needed until the overcoat on the TRISO particles had accumulated to the desired thickness. Sieving was used to eliminate undersized and oversized particles. The undersized and oversized particles were recovered by washing off the thick overcoat with methanol to expose the TRISO particles, which were dried prior to their reintroduction into the overcoater for another attempt to get the desired thickness. Some of the powder formed unfueled granules that had to be separated from the properly overcoated TRISO particles. After overcoating, the particles were air-dried for storage. This process took a few days to prepare sufficient overcoated TRISO particles to form compacts in the laboratory.

The AGR-5/6/7 experiments used the A3-27 style formulation to overcoat TRISO particles in a Freund-Vector Lab-3 Granuex unit (Figure 15), designed to coat particles for the pharmaceutical industry. In this process, the TRISO particles are placed in a rotating bowl with a fine slit around the upper perimeter of the bowl. Air was blown up through the slit to fluidize the particles in coordination with bowl rotation. This action produced a helical path in the particles, forming a toroidal "rope." Water was injected as a mist into the bed of circulating TRISO particles and the resinated graphite powder was blown in through a port diametrically opposite of the water nozzle. The water provided the necessary surface tension for the powder to stick to the TRISO particles. At the conclusion of the powder addition, the water flow was terminated, and heated air $\left(60^{\circ} \mathrm{C}\right)$ was blown down into the bowl until the particle stream reached $25^{\circ} \mathrm{C}$. The bed was not warmed more than this to preclude premature curing of the resin. Subsequent drying in a vacuum dryer removed only a few additional grams of water from nearly $4 \mathrm{~kg}$ of overcoated particles. The overcoating process was highly efficient in that over $98 \%$ of the resinated graphite powder was deposited on the particles and a $2 \mathrm{~kg}$ charge of TRISO particles could be overcoated in approximately one hour. Vacuum drying took another hour to complete. 


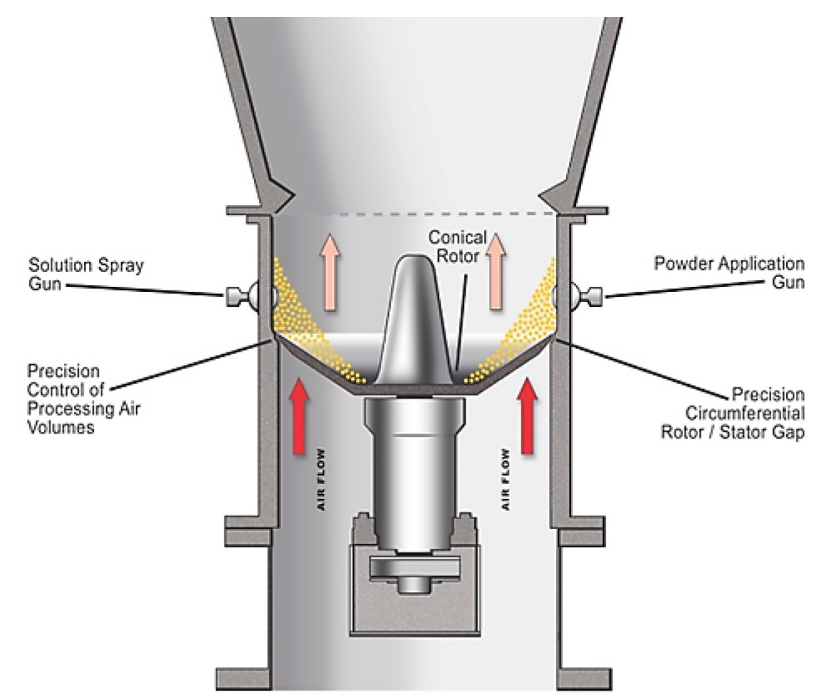

Figure 15. Illustration of the Freund-Vector Lab-3 Granuex equipment cross section.

Overcoated particles were glossy and more spherical than the uncoated TRISO particles and the finished particle size was very narrowly distributed. Sieving of the overcoated particles was not employed during compacting development trials, but was employed for AGR-5/6/7 fuel fabrication to reject any oversized, poly-kernel particles.

Early efforts to develop the process for fabricating compacts with a nominal packing fraction of $25 \%$ were attempted by first overcoating the TRISO particles with enough resinated graphite to achieve a nominal $40 \% \mathrm{PF}$, which was about half of the overcoat thickness of the overcoat for compacts at $25 \% \mathrm{PF}^{6}{ }^{6}$ The overcoated particles were then unloaded, split into two charges, and reloaded in the overcoater to continue adding overcoat to the $25 \%$ PF. Interrupting the overcoating in this fashion proved unsuccessful. Attempting to apply additional overcoat usually resulted in the initial overcoat sloughing from the TRISO and forming a moist, amorphous mass of TRISO particles and graphite sludge. Success was attained, however, by reducing the initial coater charge by nearly half and applying the overcoat in a single, continuous operation (Table 9). The rotor speed was also reduced to avoid excessive strain the thick, damp overcoat.

All of the compacts fabricated for the AGR-5/6/7 experiments were made using TRISO particle Lot J52R-16-98005. The target quantity of resinated graphite to apply to the TRISO particles was calculated based on the desired uranium loading and not the nominal packing fractions.

Table 9. TRISO-particle overcoating-process parameters.

\begin{tabular}{|l|c|c|c|c|}
\hline \multicolumn{1}{|c|}{ Parameter } & $\mathbf{4 0 \%}$ PF Compacts & \multicolumn{2}{c|}{$\mathbf{2 5 \%}$ PF Compacts } \\
\hline $\begin{array}{l}\text { Overcoating } \\
\text { Batch J52R-16-nnnnn }\end{array}$ & 11034 & 11035 & 11036 & 11037 \\
\hline Overcoater charge mass (g) & 2000 & 2000 & 1034 & 1034 \\
\hline Resinated graphite powder (g) & 1912 & 1841 & 1845 & 1845 \\
\hline Water (g) & 1873 & 1813 & 1836 & 1807 \\
\hline Bowl rotor speed (RPM) & 300 & 300 & 250 & 250 \\
\hline Powder feed rate (g/min) & $13.5 \pm 2.0$ & $13.9 \pm 1.7$ & $13.6 \pm 1.5$ & $13.6 \pm 0.7$ \\
\hline
\end{tabular}




\subsection{Compact Fabrication}

A volumetric feeder was used to charge the overcoated TRISO particles to the die cavities in the press. The volume of the charge was controlled by the internal volume of a hollow cylindrical feeder insert. Slight batch-to-batch differences in the density and mass of the applied overcoat and the resultant diameters of the overcoated TRISO particles necessitated that a few compacts be pressed and their dimensions be measured to ensure that the appropriate volumetric feeder insert was employed before each batch was pressed. Inserts were acquired in a set with increments of $0.1 \mathrm{~cm}^{3}$, which was somewhat too coarse of an increment for fine control of the compact lengths. Future feeder designs should use a mass feeder or a volumetric feeder with an adjustable charge volume that will not require shutting down the process to target the desired compact length.

The overcoated TRISO particle batches were not blended because of concern that the blending operation could cause the overcoat to crumble and loose mass. Each batch of overcoated TRISO particles (J52R-16-1103n) was pressed into "green" or compacts (J52R-16-1314n) and heat treated to form the final compact batches (J52R-16-1415n).

TRISO particles bear a portion of the compacting force. The higher the intended packing fraction, the more force is needed to achieve the desired matrix density and compact length. It will be noted in Table 10 that the force required to form the compacts at $40 \% \mathrm{PF}$ is $11 \%$ higher than the force used for those at $25 \% \mathrm{PF}$. Higher packing fractions also result in more frequent particle-to-particle contacts where the resinated graphite overcoat has been displaced, especially near the compact surfaces.

Table 10. Compacting process parameters.

\begin{tabular}{|c|c|c|c|c|}
\hline \multicolumn{5}{|c|}{ Compacting } \\
\hline Parameter & \multicolumn{2}{|c|}{ 40\% PF Compacts } & \multicolumn{2}{|c|}{$25 \%$ PF Compacts } \\
\hline Batch J52R-16-nnnnn & & & & \\
\hline Overcoated TRISO & 11034 & 11035 & 11036 & 11037 \\
\hline 'Green' Compacts & 13144 & 13145 & 13146 & 13147 \\
\hline Feeder insert volume $\left(\mathrm{cm}^{3}\right)$ & \multicolumn{2}{|c|}{6.4} & \multicolumn{2}{|c|}{7.2} \\
\hline Die body temperature $\left({ }^{\circ} \mathrm{C}\right)$ & \multicolumn{2}{|c|}{171} & \multicolumn{2}{|c|}{171} \\
\hline Die cavity temperature, $\left({ }^{\circ} \mathrm{C}\right)$ & \multicolumn{2}{|c|}{$\sim 165$} & \multicolumn{2}{|c|}{$\sim 165$} \\
\hline Hold at punch stroke position ${ }^{\mathrm{a}}$ & \multicolumn{2}{|c|}{$11 \mathrm{~s} @ 217 \mathrm{~mm}$} & \multicolumn{2}{|c|}{$10 \mathrm{~s} @ 214 \mathrm{~mm}$} \\
\hline Hold at force & \multicolumn{2}{|c|}{$40 \mathrm{~s} @ 5 \mathrm{kN}$} & \multicolumn{2}{|c|}{$39 \mathrm{~s} @ 4.5 \mathrm{kN}$} \\
\hline
\end{tabular}

The die body temperatures were set to achieve a desired die cavity temperature of $165^{\circ} \mathrm{C}$. The cavity temperature was measured using an aluminum plug with an embedded thermocouple that was inserted into the cavities. It is recognized that measurement with a plug on a static system is not fully representative of the cavity temperature of a press in an operation that is repeatedly filled with cool, overcoated TRISO particles. As the resonated-graphite overcoat warms to approximately $115^{\circ} \mathrm{C}$, the resin begins to soften and increases the malleability of the overcoat. Near $140^{\circ} \mathrm{C}$, the overcoat viscosity begins increasing due to resin cross-linking and curing. Pressing parameters were adjusted, based on estimates of thermal conductivity and die-cavity fill depth, to set a top-punch hold elevation where the punch has compressed the TRISO pile sufficiently to deform the overcoat and increase the particle-wall and particle-particle contact areas; thereby increasing the rate at which heat is transferred to the center of the pile. The intent was to allow the overcoat in the center of the pile to warm and soften, without overly curing the overcoat in contact with the heated die wall, before continuing to full compaction. 
Additional refinement to the times and temperatures will be necessary for a production-scale process to attain the desired particle distribution within the compact and the desired graphitic matrix integrity and density. Malleable overcoat is extruded into the interstitial spaces between particles during compaction. As a natural consequence of loosely filling cylindrical cavities with spherical particles, the void fraction is greatest along the die walls and punch surfaces. This results in a higher packing fraction of TRISO particles at the compact surfaces as particles move with the fluid matrix to fill the voids. The less viscous overcoat flows more readily, thus timing the compaction so that the overcoat on the particles near the die wall has begun to stiffen while the overcoat within the core of the pile is less viscous. This will encourage a more-uniform packing fraction and fewer particle-to-particle contact points. AGR-5/6/7 fuel was pressed using hold points and hold times calculated from imprecise thermal-conductivity values for the overcoat. The settings produced usable fuel compacts that have a measurably higher packing fraction near the exterior surfaces as observed using X-ray computed tomography scans (Figure 16), suggesting that the temperature in the center of the pile was not yet optimal.

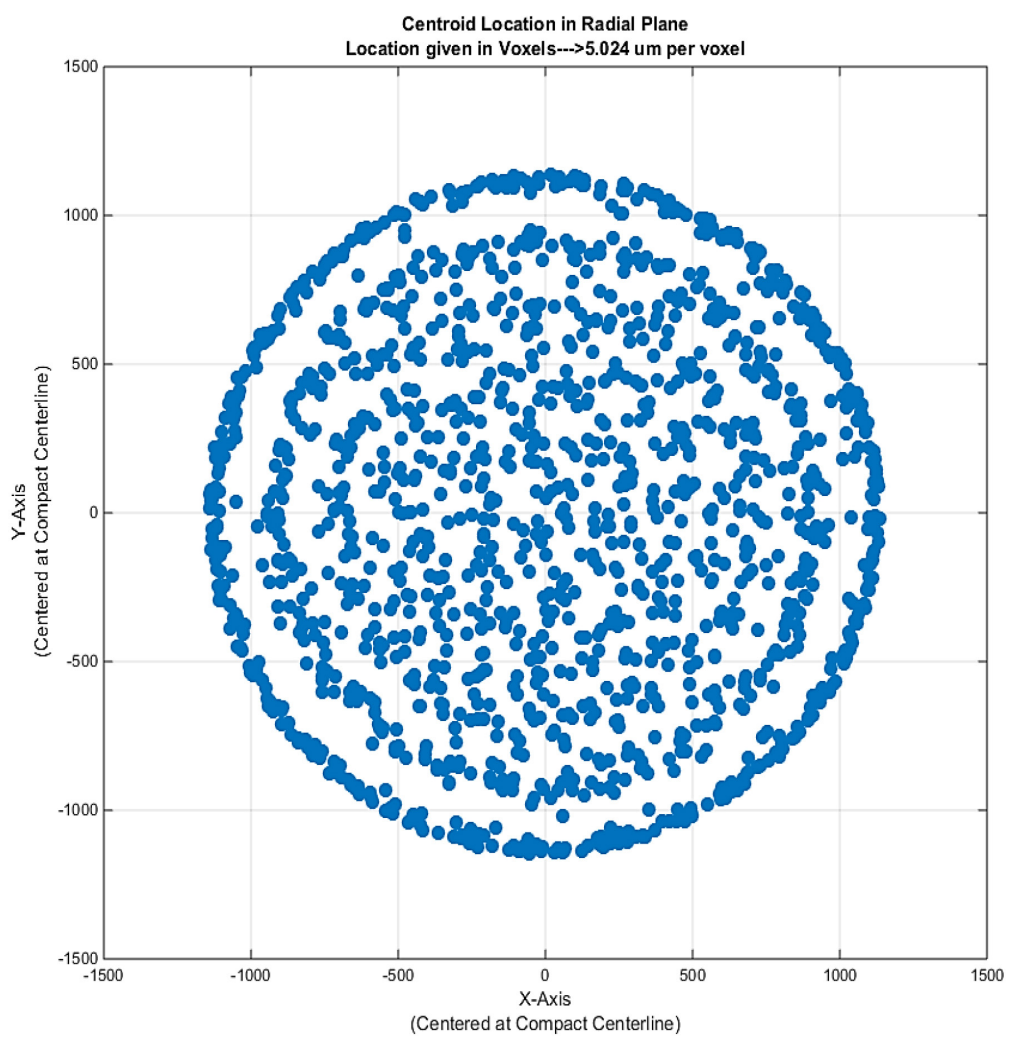

Figure 16. Example kernel map (X-ray CT) on a compact radial cross-section.

As anticipated, variations in the packing density within the volumetric inserts resulted in greater variability in the mass of particles charged to the die cavities and greater variability in compact length than when weighed charges were used in laboratory-scale fuel-fabrication efforts for previous irradiation experiments. Compacts made to a nominal $25 \%$ PF of TRISO particles required a thicker overcoat on the particles and exhibit a higher standard deviation on compact length than those with a $40 \% \mathrm{PF}$.

The standard deviation of the compact length and masses could be reduced by installing a vibrator on the volumetric feeder to ensure more consistent filling of the volumetric inserts and larger feeder funnel orifices could be used to reduce bridging when handling heavily overcoated particles while fabricating compacts with low packing fractions.

Given the current configuration for the volumetric feeder and available volumetric inserts, it was recognized that some compacts could fall outside of the specification for length. The compact length 
specification was set to ensure a uniform fuel-stack height for the test train capsule and is probably more restrictive than what will be needed for reactor fuel.

\subsection{Compact Heat Treatment}

The resin in the compacts is partially cured before the compacts are ejected from the die cavities. A partial cure has the advantages of taking less time than a "full" cure, having a lower probability of bonding the compacts to the die wall, and the resin still allows for some relaxation of internal stresses within the compact upon ejection. Before the compact is suitable for use in a reactor, it needs to be thermally and chemically stable. This is achieved by heat treating the compact to drive off adsorbed moisture, complete the cure, gasify residual hardening agents, carbonize the resin, and dimensionally stabilize the compacts.

Curing takes place when the HMTA is warm enough to decompose and induce cross-linkages in the phenolic resin. It is essentially complete before the compact temperature reaches $250^{\circ} \mathrm{C}$ (Figure 17), at which point the resin begins to pyrolyze to an amorphous, vitreous carbon. The evolution of gases from the compact initiates with low-molecular-weight gases $\left(\mathrm{H}_{2} \mathrm{O}, \mathrm{NH}_{3}\right.$, etc.) during the curing phase and progresses toward higher-molecular-weight aromatic compounds toward the end of the pyrolysis phase.

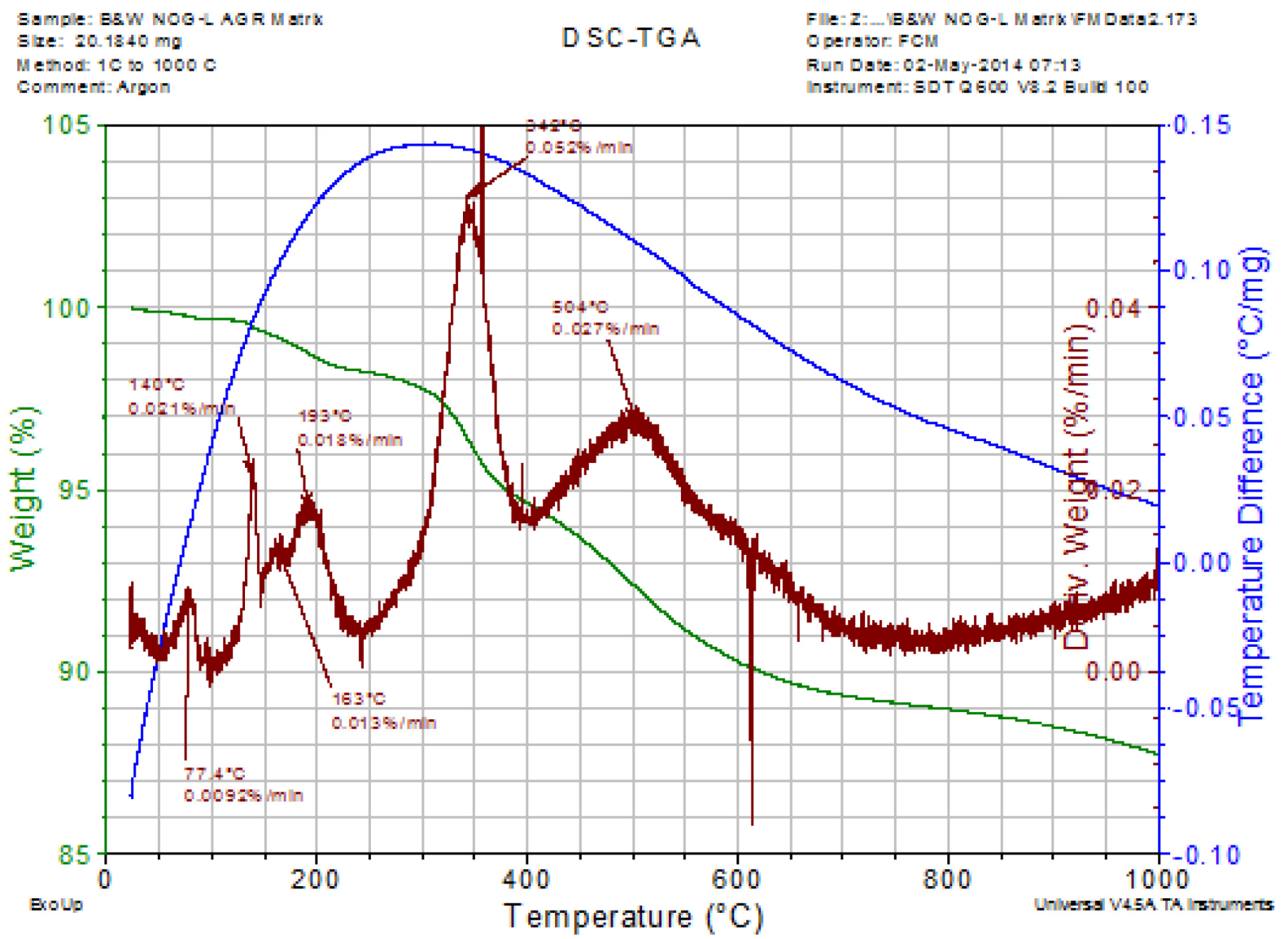

Figure 17. DSC-TGA plot of resinated graphite pyrolysis at $1{ }^{\circ} \mathrm{C} / \mathrm{min}$.

For a given weight loss, the volume of evolved gases is greater at lower temperatures when the compact has less open porosity and is less dimensionally stable than at higher temperatures when the converse is true. Early development efforts with surrogate TRISO produced circumferential cracking and bulging on the sides of the compacts, presumably from an overly aggressive thermal profile, (i.e., "furnace schedule") during heat treatment. 
The furnace internal-pressure and temperature profiles were controlled to reduce internal-pressure buildup within the compacts during initial heat treatment. After the pre-start draw down of the internal furnace pressure to about 50 mTorr, which ensured that the furnace was sealed and removed moisture and oxygen, the internal furnace pressure was increased to 695 Torr (absolute), with a dry argon for the duration of resin curing and carbonization. The near-atmospheric pressure reduced volume of evolved gases and the pressure differential between the compact interior and exterior. After $900^{\circ} \mathrm{C}$ was reached and held for half an hour, the furnace was evacuated to sub-millitorr pressures for the final heat treatment to $1800^{\circ} \mathrm{C}$. Furnace-temperature ramp rates, derived on the differential scanning calorimetry, thermogravimetric analysis (DSC-TGA) data, were controlled such that the mass loss rate of volatile compounds slowly increased during the course of the heat treatment. Thus, when the evolved gases had low molecular weights (MWs), the compact mass-loss rate was also low. Toward the end of carbonization, when evolved gases had higher MWs and compact pores were more open, the mass-loss rate was relatively high. These pressure- and temperature-control strategies eliminated formation of visible cracks and bulges on the compact surfaces.

Figure 18 shows the idealized furnace-temperature ramp rate (blue bars) as a function of furnace temperature that would linearize the mass loss from a loose pile of resinated graphite powder in a DSC-TGA (assumed to be representative of a formed compact). Also shown in this figure and in Table 11 is the temperature ramp rate that was employed in the fabrication of the fuel compacts. The time required to reach $900^{\circ} \mathrm{C}$ was $48 \%$ longer than had been used during the development activities when circumferential cracks and bulges were observed in compacts. The slower temperature ramps are believed to have reduced internal pore pressures during resin curing and carbonization.

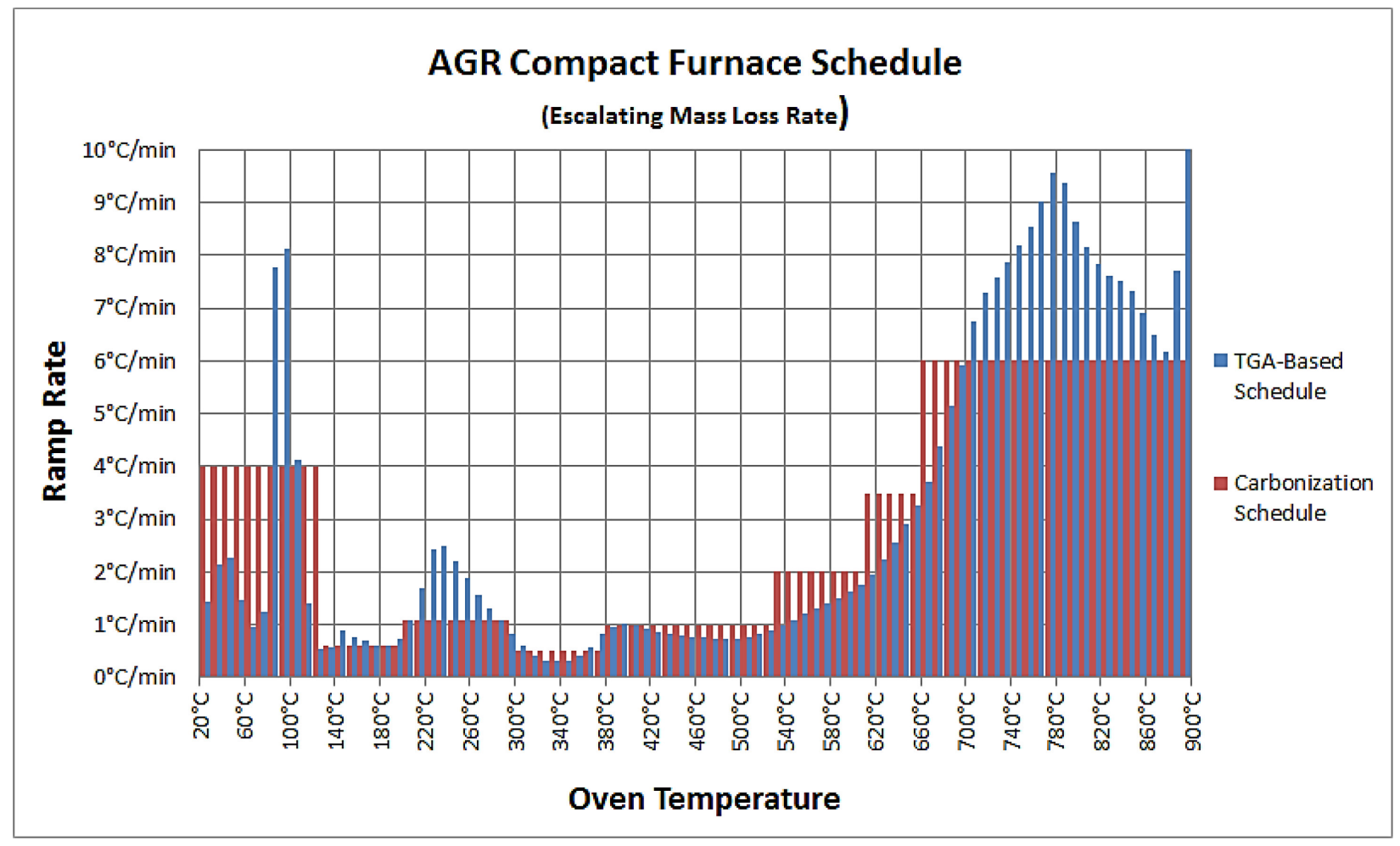

Figure 18. Furnace temperature ramp rate schedule.

Figure 19 shows the furnace-temperature profile and the estimated compact mass-retention profile computed from the temperature profile and from the DSC-TGA data. The temperature ramp, following resin carbonization, from 900 to $1800^{\circ} \mathrm{C}$ was performed in strong vacuum from $2 \mathrm{mTorr}$ down to 
$0.3 \mathrm{mTorr}$ absolute pressure. This final phase in the heat treatment ensured devolatilization and dimensional stabilization of the compacts.

Table 11. AGR-compact furnace-temperature schedule.

\begin{tabular}{|c|c|c|c|c|c|c|}
\hline \multicolumn{2}{|c|}{$\begin{array}{c}\text { Node } \\
\text { Temperatures }\end{array}$} & \multirow[b]{2}{*}{ Ramp Rate } & \multirow{2}{*}{$\begin{array}{c}\text { Absolute } \\
\text { Pressure }^{\text {a }}\end{array}$} & \multirow[b]{2}{*}{ Hold } & \multirow{2}{*}{$\begin{array}{c}\text { Step } \\
\text { Duration }\end{array}$} & \multirow{2}{*}{$\begin{array}{l}\Sigma \text { Time } \\
\text { hh:mm }\end{array}$} \\
\hline $\mathbf{n}_{\mathbf{i}}$ & $\mathbf{n}_{\mathbf{i}+\mathbf{1}}$ & & & & & \\
\hline $20^{\circ} \mathrm{C} \rightarrow$ & $\rightarrow \quad 130^{\circ} \mathrm{C}$ & $4.0^{\circ} \mathrm{C} / \mathrm{min} \quad\left(240^{\circ} \mathrm{C} / \mathrm{hr}\right)$ & $51-423$ mTorr & & $28 \mathrm{~min}$ & $0: 28$ \\
\hline $130^{\circ} \mathrm{C} \rightarrow$ & $\rightarrow \quad 200^{\circ} \mathrm{C}$ & $0.60^{\circ} \mathrm{C} / \mathrm{min} \quad\left(36^{\circ} \mathrm{C} / \mathrm{hr}\right)$ & $423-695$ mTorr & & $117 \mathrm{~min}$ & $2: 24$ \\
\hline $200^{\circ} \mathrm{C} \rightarrow$ & $\rightarrow \quad 300^{\circ} \mathrm{C}$ & $1.10^{\circ} \mathrm{C} / \mathrm{min} \quad\left(66^{\circ} \mathrm{C} / \mathrm{hr}\right)$ & 695 mTorr & & $91 \mathrm{~min}$ & $3: 55$ \\
\hline $300^{\circ} \mathrm{C} \rightarrow$ & $\rightarrow \quad 380^{\circ} \mathrm{C}$ & $0.50^{\circ} \mathrm{C} / \mathrm{min} \quad\left(30^{\circ} \mathrm{C} / \mathrm{hr}\right)$ & 695 mTorr & & $160 \mathrm{~min}$ & $6: 35$ \\
\hline $380^{\circ} \mathrm{C} \rightarrow$ & $\rightarrow \quad 530^{\circ} \mathrm{C}$ & $1.00^{\circ} \mathrm{C} / \mathrm{min} \quad\left(60^{\circ} \mathrm{C} / \mathrm{hr}\right)$ & 695 mTorr & & $150 \mathrm{~min}$ & 9:05 \\
\hline $530^{\circ} \mathrm{C} \rightarrow$ & $\rightarrow \quad 610^{\circ} \mathrm{C}$ & $2.0^{\circ} \mathrm{C} / \mathrm{min} \quad\left(120^{\circ} \mathrm{C} / \mathrm{hr}\right)$ & 695 mTorr & & $40 \mathrm{~min}$ & $9: 45$ \\
\hline $610^{\circ} \mathrm{C} \rightarrow$ & $\rightarrow \quad 660^{\circ} \mathrm{C}$ & $3.5^{\circ} \mathrm{C} / \mathrm{min} \quad\left(210^{\circ} \mathrm{C} / \mathrm{hr}\right)$ & 695 mTorr & & $14 \mathrm{~min}$ & $9: 59$ \\
\hline $660^{\circ} \mathrm{C} \rightarrow$ & $\rightarrow \quad 900^{\circ} \mathrm{C}$ & $6.0^{\circ} \mathrm{C} / \mathrm{min}$ & 695 mTorr & & $40 \mathrm{~min}$ & $10: 39$ \\
\hline & $900^{\circ} \mathrm{C}$ & & 695 mTorr & $30 \mathrm{~min}$ & $30 \mathrm{~min}$ & 11:09 \\
\hline $900^{\circ} \mathrm{C} \rightarrow$ & $\rightarrow \quad 1800^{\circ} \mathrm{C}$ & $\left(900^{\circ} \mathrm{C} / \mathrm{hr}\right)$ & $1.9-0.8 \mathrm{mTorr}$ & & $60 \mathrm{~min}$ & $12: 09$ \\
\hline & $1800^{\circ} \mathrm{C}$ & & $0.8-0.3$ mTorr & $60 \mathrm{~min}$ & $60 \mathrm{~min}$ & 13:09 \\
\hline
\end{tabular}

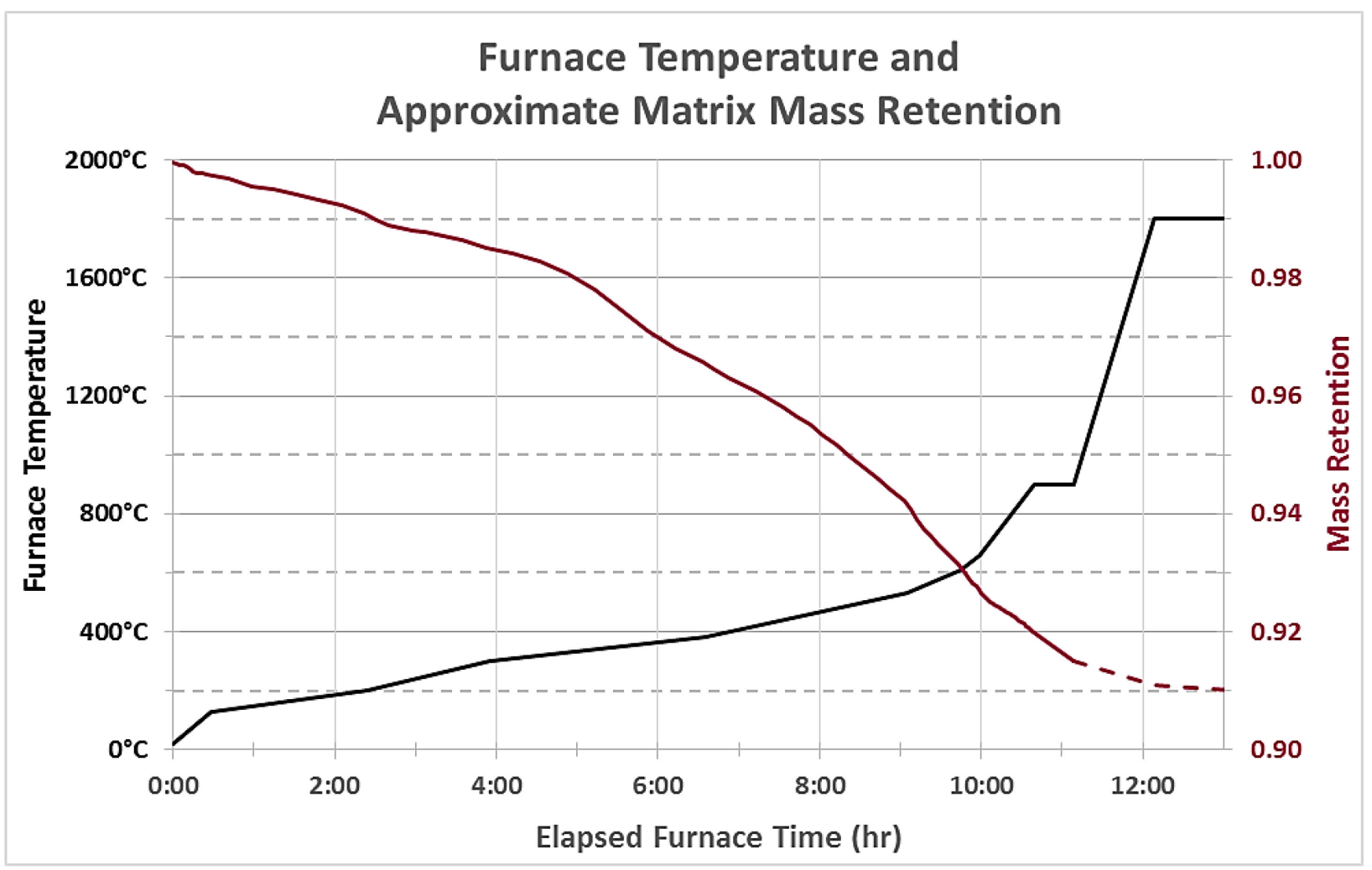

Figure 19. Furnace temperature and calculated compact mass retention.

To expedite delivery of compacts for the AGR-5/6/7 irradiation experiment, compacts from all four compact batches were included in one of four furnace runs to cure and carbonize the resin and to dimensionally and chemically stabilize the compacts. The furnace runs are indicated by a letter (A-D), 
which was appended to the fired compact batch designation (e.g., J52R-14154A). The AGR-5/6/7 test capsules were loaded with compacts from the first furnace run (A) and all four compact batches. Compact characterization was done with compacts from furnace runs $\mathrm{C}$ and $\mathrm{D}$. Furnace run $\mathrm{B}$ was interrupted between resin carbonization and matrix stabilization due to an instrument malfunction, so it was excluded from use in the test train and compact characterizations, although previous AGR irradiation campaigns also used an interruption at this stage in the thermal treatment of the compacts.

Photographs of two fuel compacts, heat treated under these conditions, are shown in Figure 20. Calculated matrix densities for both compacts of both packing fractions were generally over $1.72 \mathrm{~g} / \mathrm{cm}^{3}$, which should ensure good heat transfer.

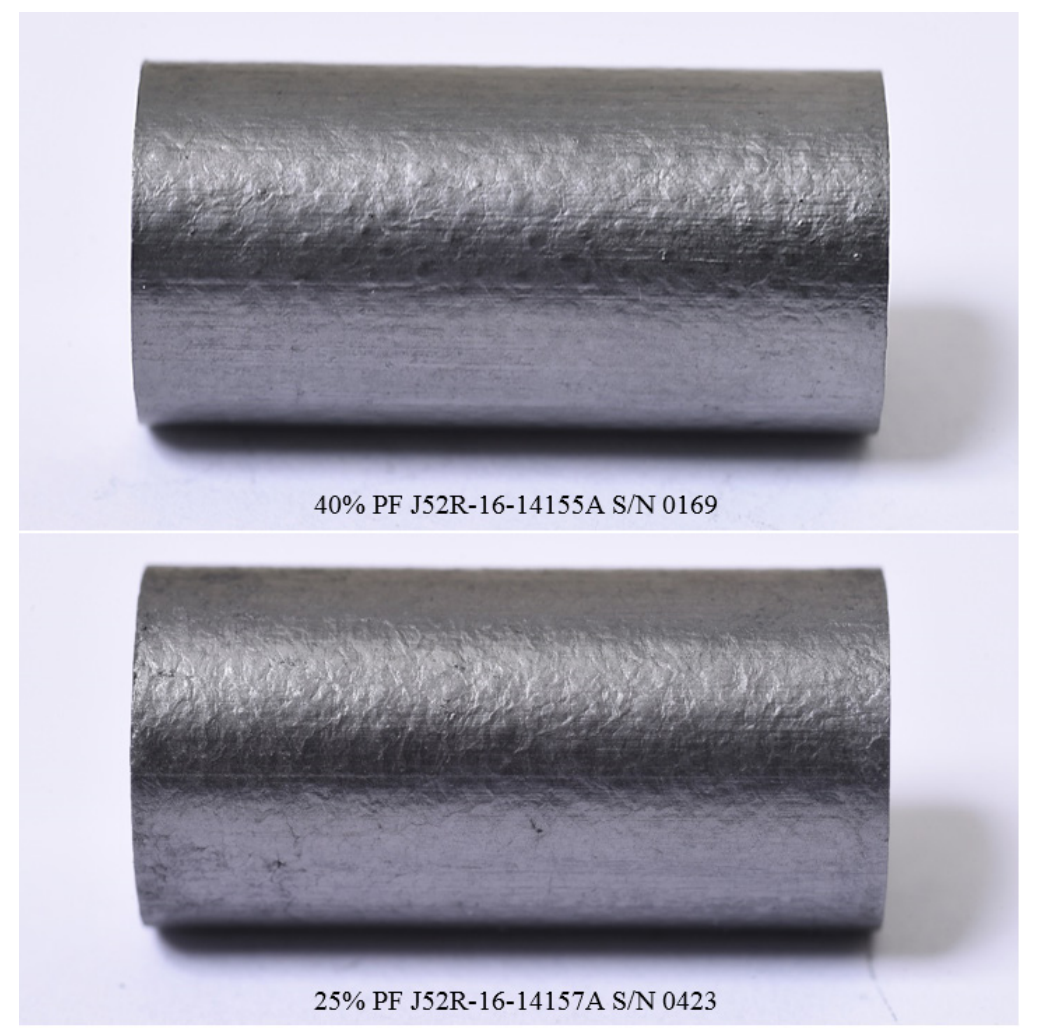

Figure 20. Photos of AGR-5/6/7 fuel compacts.

\subsection{Fuel Compact Characterization}

\subsubsection{Compact Dimensional Analyses}

Every compact was individually weighed and measured. The diameter was determined from three sets of orthogonal diametric measurements along three axial positions. The compact length was determined from two measurements taken with a $\sim 90$ degree rotation. From these measurements, the means were determined.

All compacts lost mass and volume during thermal treatment (Figure 21). Compacts fabricated at the nominal 25\% PF, had more matrix material than those with a higher PF and exhibit greater compact mass and volume loss during thermal treatment. Compacts of both PFs had higher weight retention than the loose resinated graphite matrix powder data shown in Figure 19, because of greater exposure of the resin to curing agents.

Axial compact growth during heat treatment, a phenomenon not observed with the lower density A3-3 matrix from earlier AGR experiments, manifested itself during the development activities with the 
A3-27 matrix formulation. An association between axial compact growth and the formation of circumferential cracks was postulated. Efforts to reduce the circumferential cracking were also effective in reducing the extent of axial compact growth, which averaged merely $0.16 \%$ during thermal treatment or $\sim 0.04 \mathrm{~mm}$ for the compacts shipped to the INL for inclusion in the AGR-5/6/7 experiment (Figure 22). Compacts have historically exhibited diametric shrinkage during thermal treatment.

Some differences are observed in the surface texture of the compacts of the two PFs. The locations of TRISO particles near the compact surface are more discernable at $40 \%$ PF than at the lower PF; giving the higher PF compact a deceptive appearance of having a higher matrix density. The difference in the mean calculated matrix densities for the two compact lots is less than $1 \%$, with the $25 \% \mathrm{PF}$ compacts having the higher mean matrix density.

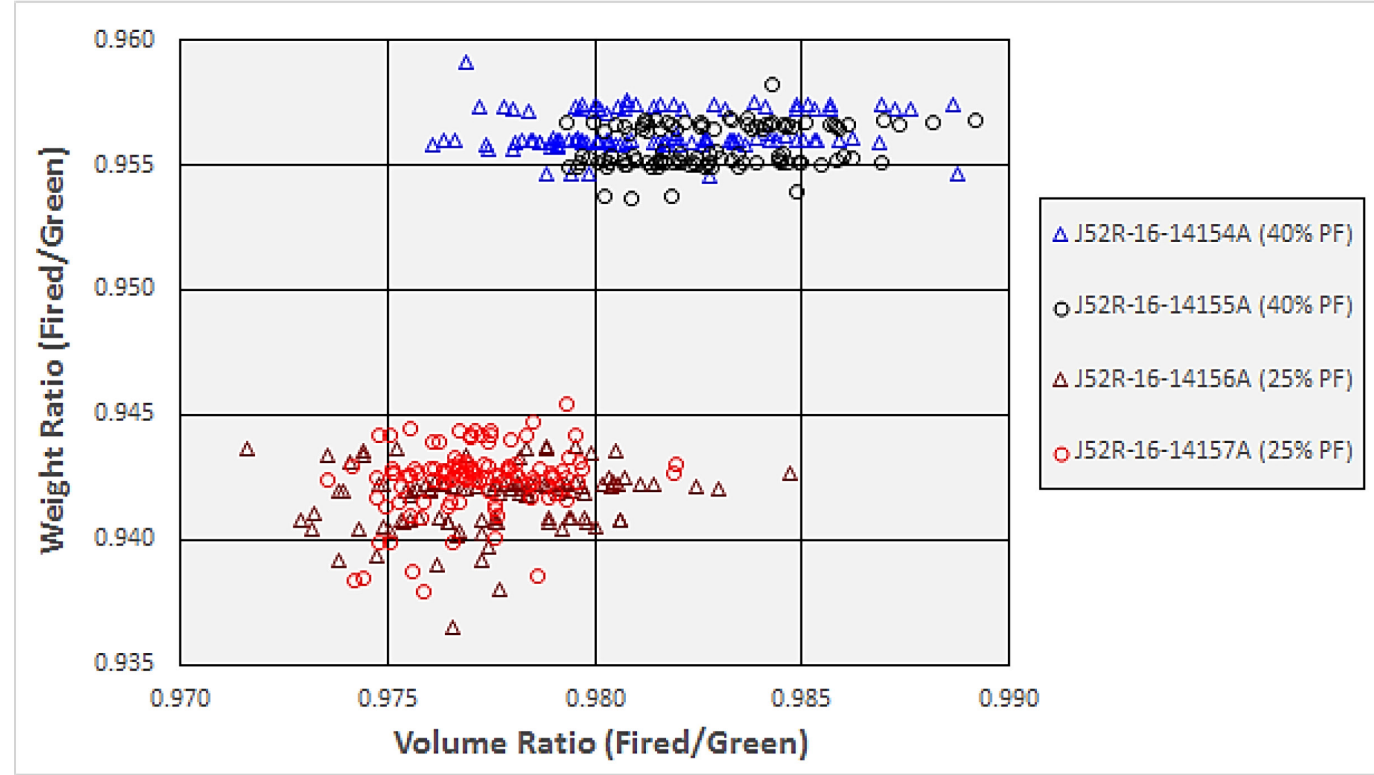

Figure 21. Weight and volume ratios in AGR-5/6/7 compacts.

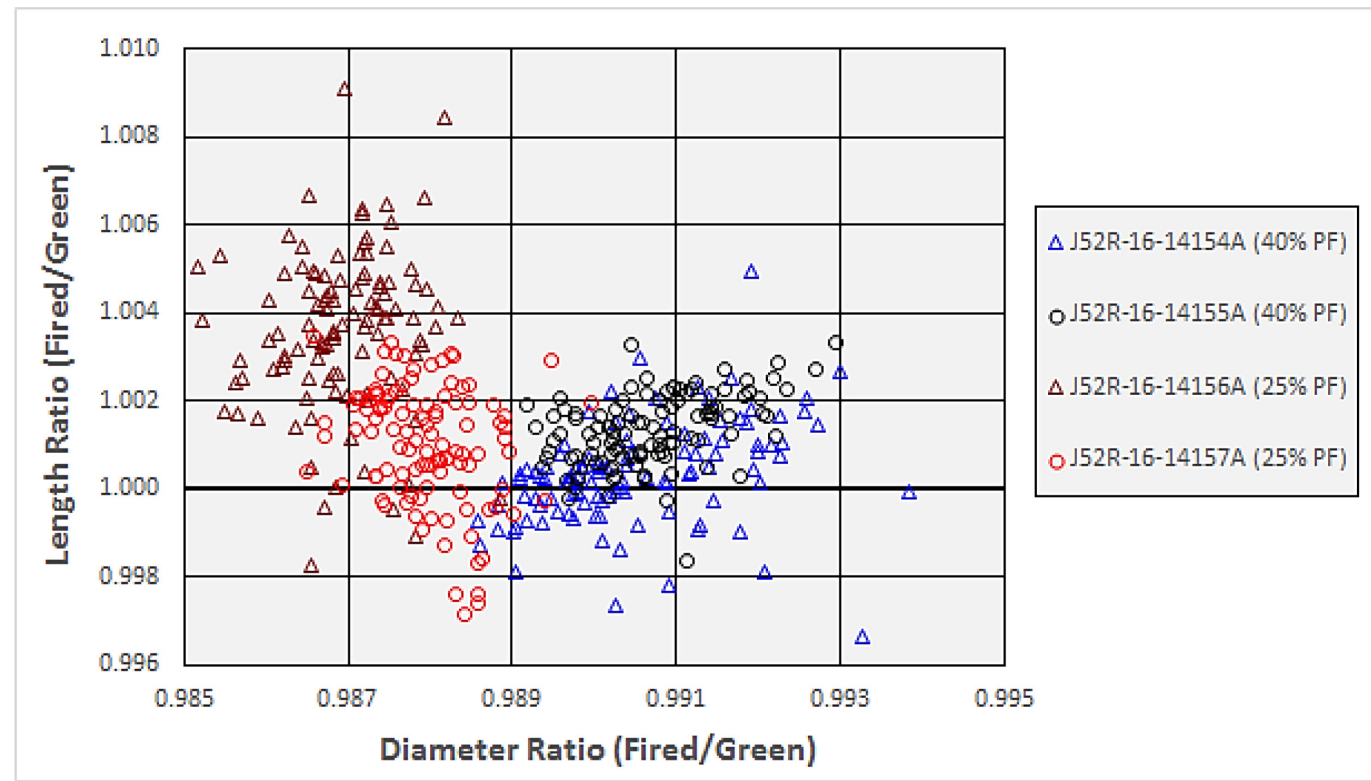

Figure 22. Length and diameter ratios in AGR-5/6/7 compacts. 
Figure 21 reveals a bifurcation in the individual compact batch populations for the weight-ratio metric (e.g., in J52R-16-14154A and J52R-16-14155A). This suggests that compacts formed in about one-half of the process may differ in densification during compaction; leading to some differences in mass loss during thermal treatment. This phenomenon is observed in a higher mass loss of loose resinated-graphite powder on the TGA-DSC instrument than the mass loss of compacted powder and is likely correlated to the fraction of evolving gases that react with the resin or decompose to carbon before escaping the graphite mass. The source of the difference in compact mass retention has not been investigated, but is likely related to the press, because the individual compact batches in this data set were fired at the same time, but in separate compact boats. Figure 21 also shows that the lower PF compacts are subject to greater volumetric decreases as well as greater mass loss.

Figure 22 shows that the higher PF compacts are dimensionally more stable than those with a lower PF. Diametric shrinkage and, to a lesser extent, axial growth are both more pronounced with lower PF compacts. The lower PF compacts also exhibit a broader distribution in axial growth than the higher PF compacts.

\subsubsection{Compact Defect-fraction Definitions}

The three defect fractions of most concern are the dispersed-uranium fraction (DUF), the exposedkernel fraction (EKF), and the silicon carbide defect fractions (SDF). How these three defect fractions were quantified for the AGR-5/6/7 compact characterization is prescribed in the AGR-5/6/7 fuel specification. ${ }^{1}$

The DUF is a variable-property and metric for the quantity of uranium dust or contamination that resides in the $\mathrm{OPyC}$ layer and the outer few microns of the $\mathrm{SiC}$ layer. The dispersed uranium is a potential source of fission products that are not contained within the TRISO particle. Dispersed uranium is likely associated with friable or frangible kernels. DUF is quantified using data from the pre-burn and post-burn analyses that exhibit less than half of a kernel equivalent of uranium in the leachates. True DUF should not change as TRISO particles are overcoated and compacted, because it is not associated with damage to coating layers.

The EKF is an attribute-property and metric for the presence of kernels in TRISO particles that have cracked, broken, or missing coating layers. Because sieving is employed to reject undersized TRISO particles, the probability of a 'naked' kernel being incorporated into a fuel compact is small. The EKF quantifies particles with through-layer defects occurring during TRISO coating or subsequent handling, overcoating, or fuel-compact pressing operations.

The SDF is an attribute-property and metric for TRISO particles with intact OPyC, but a porous, cracked, or missing $\mathrm{SiC}$ layer. The fuel kernels of particles with only silicon carbide defects are not exposed to the leachants until after the outer pyrocarbon an internal carbon layers are oxidized during the "burn" back of the OPyC. It has been assumed that the SiC layer would not crack without shearing the adjacent pyrocarbon layers; meaning that the method measured only porous or missing SiC layers and should be independent of the measured EKFs. ORNL observed that the SDF results exhibit some correlation with the EKF; suggesting a non-trivial probability of the $\mathrm{SiC}$ layer cracking without concurrent damage to the OPyC layer. ${ }^{7}$

\subsubsection{Defect Analyses}

The method to obtain the pre-burn and post-burn leach data involves electrolytic deconsolidation of the compacts in groups of five compacts (a.k.a., a "compact clutch") followed by a suite of nitric acid leaches, the thermal oxidation of the $\mathrm{OPyC}$ and exposed inner carbon layers, and a final suite of nitric acid leaches. This method was developed for earlier irradiation experiments when the compacts were formed from an A3-3 style matrix that had lower matrix densities (less graphite per unit compact volume) and coarser graphite particles. The A3-27 style matrix fabricated in a jet mill resulted in mean graphite particle sizes having about one-half to one-third the effective diameters of the graphite powders in earlier 
AGR irradiations. ORNL reported that the deconsolidated compacts, made with the INL A3-27

formulation, yield a viscous, "inky" mass following deconsolidation, thus making it more difficult to separate the TRISO particles cleanly from the graphite powder slurry or the graphite from the supernate to assure thorough recovery of dissolved uranium ${ }^{8}$. Consequently, precise bifurcation of the quantified dispersed-uranium, exposed-kernel, and silicon carbide defect fractions may not be fully assured. This is believed to be the case for the analyses performed on fuel compacts at BWXT-NOG. It is also thought that anomalous instances of secondary leaches recovering more uranium that the initial leach resulted from the analytical method as it was applied to compacts using the A3-27 matrix. The precision with which leached uranium is attributed to specific defects will always be in question when several anomalous sets of leach data are reported. Additionally, the mathematical method of bifurcating dispersed uranium from exposed uranium or silicon carbide defects is to assign leachates containing less than half of an average kernel equivalent to the DUF and anything greater than that to the other defects. DUF measurements are typically an order of magnitude less than half of a kernel equivalent for a 5compact clutch, so instances where 0.15 or greater kernel equivalents are recovered suggest that it is not truly dispersed uranium, but somehow associated with a leachable kernel fragment. The data presented below follow the historically accepted mathematical assignment of leached uranium to the respective defect fractions.

BWXT-NOG deconsolidated and analyzed 15 compact clutches with a nominal PF of $40 \%$-seven from J52R-16-14154C and eight from J52R-16-14155C. BWXT-NOG also deconsolidated and analyzed 24 compact clutches with a nominal PF of $25 \%$; 12 from both of the J52R-16-14156C and $14157 \mathrm{C}$ populations. BWXT-NOG was instructed to pool the results of clutches from compact batches having the same nominal packing fraction to simulate a production environment where compacts might be pulled randomly from several batches of the same packing fraction. Multiple clutch leach exhibited anomalies or results seemed to be clustered by the day the samples were processed.

To resolve questions arising from compact characterizations performed at BWXT-NOG, samples of compacts and overcoated, but uncompacted TRISO particles were sent to ORNL for confirmatory analyses. These samples included 20 clutches of $40 \%$ PF compacts from J52R-16-14154C and D, 12 clutches of $25 \%$ PF compacts from J52R-16-14156C and D, and the particle equivalent of 8 clutches from each batch of TRISO overcoated for 40\% PF compacting (J52R-16-11034 and J52R-16-11035). The overcoated TRISO particles were analyzed to quantify damage to the TRISO in the $40 \% \mathrm{PF}$ compacts incurred during overcoating and during compacting.

BWXT-NOG and ORNL lab data in Table 12 are pooled from all the samples analyzed by the respective laboratories. Values exceeding fuel specification maximum acceptable defect fractions are in red. Analysis of the TRISO lot, J52R-16-98005, prior to overcoating and compacting signaled the strong possibility that the DUF would not comply with the specification, which is consistent with the ORNL data for the compacts being near the limit. Doubling the sample population for the $25 \% \mathrm{PF}$ compacts at ORNL would have reduced the uncertainty in the calculated $95 \%$ confidence value, but was unlikely to bring the population into compliance with the specification, so additional analyses were not performed on that population. 
Table 12. Pooled defect-analysis results.

\begin{tabular}{|c|c|c|c|c|c|c|}
\hline Lab & $\mathbf{P F}$ & $\begin{array}{l}\text { Total } \\
\text { Clutches }\end{array}$ & Particle Count $^{a}$ & $\begin{array}{l}\text { DUF }^{\mathbf{a}} \\
95 \% \text { Confidence } \\
\text { (Mean) }\end{array}$ & $\begin{array}{l}\mathbf{E K F}^{\mathbf{a}} \\
95 \% \text { Confidence } \\
\text { (Mean) }\end{array}$ & $\begin{array}{l}\text { SDF }^{\mathbf{a}} \\
95 \% \text { Confidence } \\
\text { (Mean) }\end{array}$ \\
\hline $\mathrm{BWXT}^{\mathrm{b}}$ & \multirow{2}{*}{$40 \%$} & 15 & $258.6 \mathrm{k}$ & $\leq 5.1 \mathrm{E}-5(2.4 \mathrm{E}-5)$ & $\leq 9.4 \mathrm{E}-5(6.2 \mathrm{e}-5)$ & $\leq 9.9 \mathrm{E}-5(6.6 \mathrm{E}-5)$ \\
\hline ORNL & & 20 & $348.0 \mathrm{k}$ & $\leq 9.1 \mathrm{E}-6(7.0 \mathrm{E}-6)$ & $\leq 1.0 \mathrm{E}-4(7.2 \mathrm{E}-5)$ & $\leq 7.0 \mathrm{E}-5(4.6 \mathrm{E}-5)$ \\
\hline $\mathrm{BWXT}^{\mathrm{b}}$ & \multirow{2}{*}{$25 \%$} & 24 & $270.4 \mathrm{k}$ & $\leq 2.3 \mathrm{E}-5(1.9 \mathrm{E}-5)$ & $\leq 1.8 \mathrm{E}-5(3.7 \mathrm{E}-6)$ & $\leq 1.2 \mathrm{E}-4(8.1 \mathrm{E}-5)$ \\
\hline ORNL & & 12 & $137.4 \mathrm{k}$ & $\leq 1.3 \mathrm{E}-5(9.5 \mathrm{E}-6)$ & $\leq 3.5 \mathrm{E}-5(7.3 \mathrm{E}-6)$ & $\leq 5.7 \mathrm{E}-5(2.2 \mathrm{E}-5)$ \\
\hline \multicolumn{3}{|c|}{ Overcoated TRISO (40\% PF) } & $286.3 \mathrm{k}$ & $\leq 7.5 \mathrm{E}-6(6.7 \mathrm{E}-6)$ & $\leq 4.1 \mathrm{E}-5(2.1 \mathrm{E}-5)$ & $\leq 2.2 \mathrm{E}-5(7.0 \mathrm{E}-6)$ \\
\hline \multicolumn{3}{|c|}{ J52R-16-98005 TRISO lot } & $\begin{array}{l}\text { 319k (Pre-burn) } \\
\text { 159k (Post-burn) }\end{array}$ & $\leq \mathrm{NA}(1.04 \mathrm{E}-5)$ & $\leq 2.4 \mathrm{E}-5(9.4 \mathrm{E}-6)$ & $\leq 4.9 \mathrm{E}-5(1.9 \mathrm{E}-5)$ \\
\hline \multicolumn{4}{|c|}{ Fuel Specification } & $<1.0 \mathrm{E}-5$ & $\leq 5.0 \mathrm{E}-5$ & $\leq 1.0 \mathrm{E}-4$ \\
\hline
\end{tabular}

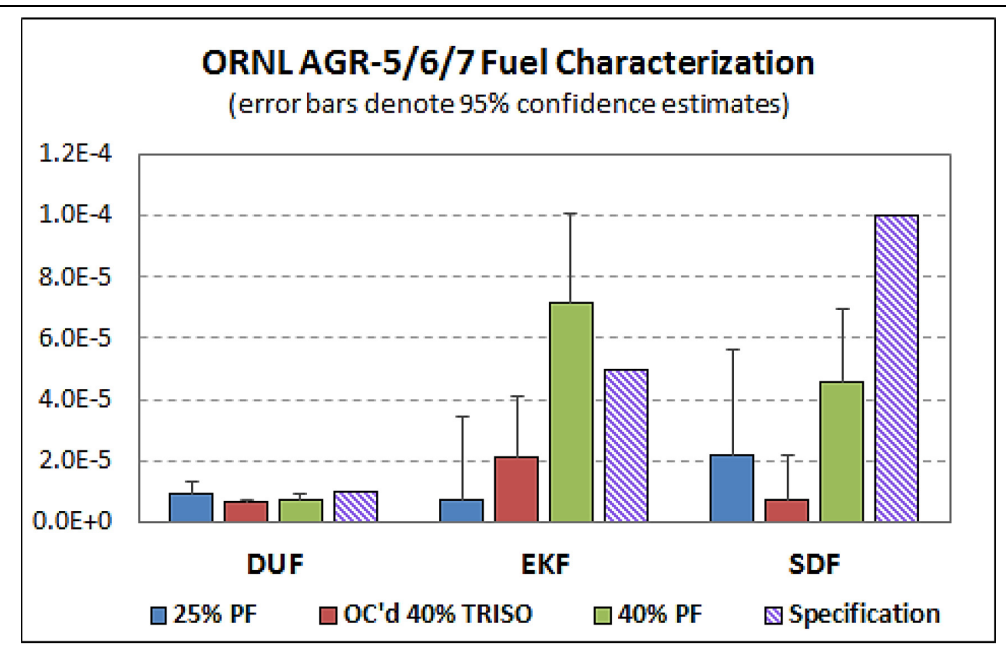

Figure 23. Compact and overcoated TRISO defect fractions quantified by ORNL.

Given that the compact-deconsolidation leach-burn-leach method was developed at ORNL and that the ORNL leach results included much fewer anomalies than the data from BWXT-NOG, the ORNL data is considered to be more accurate. Figure 23 compares the defect fractions of the $25 \%$ and $40 \% \mathrm{PF}$ compacts with residual TRISO particles that were overcoated for the $40 \%$ PF and the fuel specifications. All three populations were near the specification for the DUF; all passed the SDF specification, but the $40 \% \mathrm{PF}$ compacts clearly exhibited an increase in the EKF defect, relative to the $25 \% \mathrm{PF}$ compacts and the overcoated TRISO, revealing that TRISO particles were damaged during compaction and not significantly during overcoating. Notably, the mean SDF for the $40 \%$ PF compacts also increased, but remains within the confidence range of the $25 \% \mathrm{PF}$ compacts and below the specification. Relative to the overcoated TRISO particles, however, the increase in the SDF appears statistically significant and suggests that some damage can be done to the $\mathrm{SiC}$ layer during compaction that does not manifest in the EKF metric.

The rise in the EKF for the overcoated TRISO particles is paired with an unexpected decline in the SDF. The total quantities of uranium recovered from the three populations and from the TRISO particle 
lot is shown in Figure 24. The total of the defect fractions is relatively constant for the virgin TRISO lot, the overcoated TRISO, and the compacts formed at a $25 \% \mathrm{PF}$, but is four-fold higher for the $40 \% \mathrm{PF}$ compacts than the other populations.

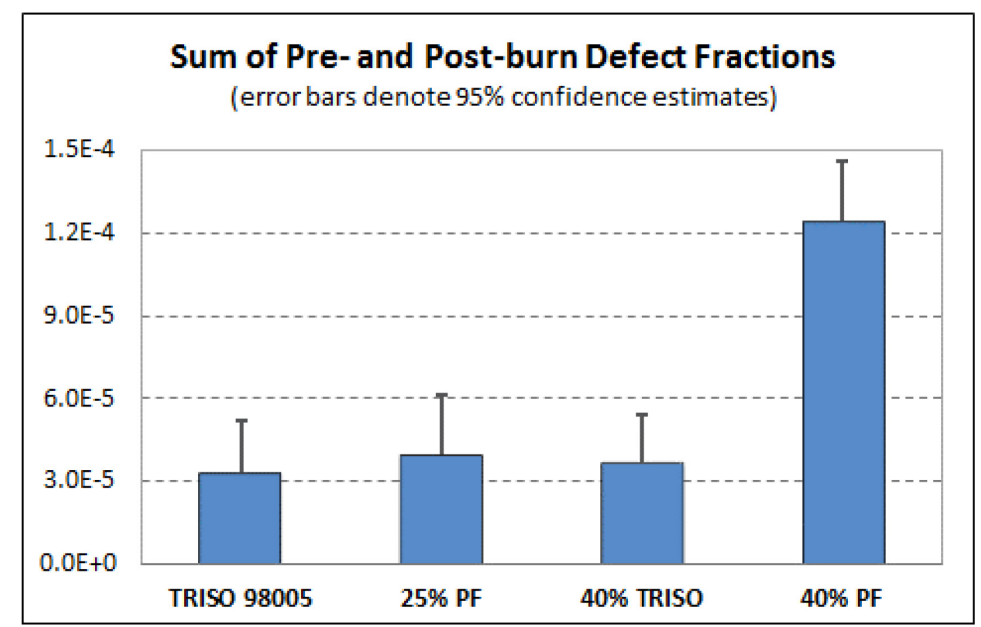

Figure 24. Total uranium leached during defect characterizations by ORNL (treated as a variable property).

The uniformity of all but the $40 \%$ PF compacts in the quantity of leached uranium (Figure 24) coupled with the variability of the calculated defect fractions (Figure 23) suggests that the defect fractions are not truly independent with the current analytical and mathematical methods. Some interdependence is observed in that high EKF values are often associated with low DUF and elevated SDF values.

\subsubsection{Chemical and Physical Analyses}

The compacts were characterized in accordance with the sample population sizes given in the sampling plan ${ }^{5}$ to ensure adequate statistics. In some instances, the minimum sample population size was exceeded to provide for better statistical representation of the mean or critical limits. When critical limits were specified, such as the compact length, the reported values are the population maxima and minima when the specification was met. In cases where the critical-limit specification was not met, the specimen count given was found outside of the specified range is given. In this case, the specification limit is reported and not the measured extremum. None of the compacts selected for the AGR-5/6/7 irradiation test train were outside of the specified ranges for length. The chemical impurities analyses are shown in Table 13.

Table 13. Chemical impurities analyses.

\begin{tabular}{|l|c|c|c|c|}
\hline \multicolumn{1}{|c|}{ Impurity $^{\mathbf{a}}$} & $\begin{array}{c}\text { BWXT } \\
\text { Pooled Data }^{\mathbf{b}}\end{array}$ & $\begin{array}{c}\text { ORNL } \\
\mathbf{( 4 0 \% \text { PF) }} \\
\mathbf{1 4 1 5 4 C}\end{array}$ & $\begin{array}{c}\text { ORNL } \\
\text { (25\% PF) } \\
\mathbf{1 4 1 5 6 C , ~ D ~}\end{array}$ & Fuel Specification \\
\hline Compact Count $^{2}$ & $24(6$ ea.) & 20 & 20 & - \\
\hline Iron $(\mu \mathrm{g})^{\mathrm{c}}$ & $5 \pm 1.28$ & $77.62 \pm 4.75$ & $48.16 \pm 5.11$ & - \\
& $\mathrm{UL} \leq 5.5$ & $\mathrm{UL} \leq 79.5$ & $\mathrm{UL} \leq 50.1$ & $\leq 25$ \\
& $\leq 1 \% \geq 9.1$ & $\leq 1 \% \geq 94$ & $\leq 1 \% \geq 65$ & $\leq 1 \% \geq 100$ \\
\hline Transition metals $(\mu \mathrm{g})^{\mathrm{c}}$ & & & & \\
$\mathrm{Cr}$ & $25 \pm 0.42$ & $0.39 \pm 0.06$ & $0.65 \pm 0.22$ & $\leq 50$ each \\
$\mathrm{Mn}$ & $10 \pm 2.57$ & $0.561 \pm 0.029$ & $0.345 \pm 0.013$ & \\
$\mathrm{Co}$ & $10 \pm 2.57$ & $0.043 \pm 0.005$ & $0.021 \pm 0.004$ & \\
\hline
\end{tabular}




\begin{tabular}{|c|c|c|c|c|}
\hline Impurity $^{\mathbf{a}}$ & $\begin{array}{c}\text { BWXT } \\
\text { Pooled Data }^{\mathrm{b}}\end{array}$ & $\begin{array}{c}\text { ORNL } \\
(40 \% \text { PF }) \\
14154 \mathrm{C} \\
\end{array}$ & $\begin{array}{c}\text { ORNL } \\
(25 \% \text { PF }) \\
14156 C, \text { D } \\
\end{array}$ & Fuel Specification \\
\hline $\mathrm{Ni}$ & $10 \pm 2.57$ & $1.24 \pm 0.26$ & $1.64 \pm 0.46$ & \\
\hline$\Sigma(\mathrm{Cr}, \mathrm{Mn}, \mathrm{Co}, \mathrm{Ni})$ & $55 \pm 7.81$ & $2.24 \pm 0.27$ & $2.65 \pm 0.51$ & 一 \\
\hline$\Sigma \mathrm{UL}$ & $\leq 1 \% \Sigma \geq 80$ & $\leq 1 \% \Sigma \geq 3.2$ & $\leq 1 \% \Sigma \geq 4.4$ & $\leq 1 \% \Sigma \geq 200$ \\
\hline Calciumm $^{c, d}(\mu \mathrm{g})$ & $\begin{array}{c}25.5 \pm 7.76 \\
\mathrm{UL} \leq 28.3 \\
\end{array}$ & $\begin{array}{c}135.21 \pm 5.83 \\
\mathrm{UL} \leq 137.5\end{array}$ & $\begin{array}{c}114.27 \pm 8.38 \\
\mathrm{UL} \leq 117.5\end{array}$ & - \\
\hline Aluminum $^{\mathrm{c}, \mathrm{d}}(\mu \mathrm{g})$ & $\begin{array}{c}27.7 \pm 16.0 \\
\mathrm{UL} \leq 33.3 \\
\end{array}$ & $\begin{array}{c}166.80 \pm 4.16 \\
\mathrm{UL} \leq 168.4\end{array}$ & $\begin{array}{c}133.95 \pm 4.33 \\
\mathrm{UL} \leq 135.6\end{array}$ & $\begin{array}{l}- \\
\leq 50\end{array}$ \\
\hline $\mathrm{Ti}+\mathrm{V}(\mu \mathrm{g})$ & & & & \\
\hline $\mathrm{Ti}$ & $10 \pm 2.57$ & $12.11 \pm 2.85$ & $9.66 \pm 0.41$ & - \\
\hline $\mathrm{V}$ & $10 \pm 2.57$ & $5.46 \pm 0.08$ & $5.54 \pm 0.08$ & - \\
\hline$\Sigma(\mathrm{Ti}, \mathrm{V})^{\mathrm{c}}$ & $20 \pm 3.63$ & $17.57 \pm 2.85$ & $15.20 \pm 0.42$ & - \\
\hline$\Sigma \mathrm{UL}$ & $\Sigma \mathrm{UL} \leq 21.3$ & $\Sigma \mathrm{UL} \leq 18.7$ & $\Sigma \mathrm{UL} \leq 15.4$ & $\Sigma \leq 240$ \\
\hline \multicolumn{5}{|c|}{$\begin{array}{l}\text { a. Impurity units are } \mu \mathrm{g} \text { per compact outside of the } \mathrm{SiC} \text { layer. } \\
\text { b. BWXT data pooled from six compacts from each of the four compact series. Averages from all sets were below the } \\
\text { analytical detection limits for the analytes, except for a few individual compacts. Integer values for the means reflect the } \\
\text { detection limits. BWXT data are the data used to certify the compacts for inclusion in the AGR-5/6/7 experiment. } \\
\text { c. Reported UL is the } 95 \% \text { upper confidence limit. } \\
\text { d. ORNL has a known cross contamination issue with } \mathrm{Al} \text { and } \mathrm{Ca} \text {. Reported values may not be accurate. }\end{array}$} \\
\hline
\end{tabular}

Characterization data for the compacts of both packing fractions are reported in Table 14 andTable 15. Data include those reported by BWXT for most properties and from ORNL for the DUF, EKF, and SDF values.

Table 14. Characterization data for nominally $40 \%$ PF compacts after heat treatment ${ }^{4}$.

\begin{tabular}{|c|c|c|c|}
\hline Property & Specification & J52R-16-14154 & J52R-16-14155 \\
\hline \multicolumn{4}{|l|}{ Variable Properties } \\
\hline $\begin{array}{l}\text { Mean uranium loading } \\
\text { (gU/compact) } \\
\text { Nominally } 40 \% \text { packing fraction }\end{array}$ & $1.36 \pm 0.10$ & $\begin{array}{l}1.370 \pm 0.005 \\
\mathrm{LL} \geq 1.370 \\
\mathrm{UL} \leq 1.370 \\
\end{array}$ & $\begin{array}{c}1.347 \pm 0.006 \\
\mathrm{LL} \geq 1.348 \\
\mathrm{UL} \leq 1.347 \\
\end{array}$ \\
\hline Calculated PF in test train capsules & - & $0.393 \pm 0.001$ & $0.393 \pm 0.001$ \\
\hline Diameter $(\mathrm{mm})$ & $\begin{array}{c}- \\
0 \leq 12.20 \\
0 \geq 12.44\end{array}$ & $\begin{array}{c}12.29 \pm 0.01 \\
0 \leq 12.25 \\
0 \geq 12.35\end{array}$ & $\begin{array}{c}12.29 \pm 0.02 \\
0 \leq 12.25 \\
0 \geq 12.34\end{array}$ \\
\hline Length $(\mathrm{mm})^{\mathrm{a}}$ & $\begin{array}{c}- \\
0 \leq 24.40 \\
0 \geq 25.30\end{array}$ & $\begin{array}{c}25.03 \pm 0.08 \\
0 \leq 24.80 \\
0 \geq 25.24\end{array}$ & $\begin{array}{c}24.69 \pm 0.10 \\
0 \leq 24.46 \\
3 \geq 25.30 \\
\end{array}$ \\
\hline Mass (g) & - & $6.71 \pm 0.02$ & $6.61 \pm 0.03$ \\
\hline Compact density $\left(\mathrm{g} / \mathrm{cm}^{3}\right)$ & - & $2.26 \pm 0.01$ & $2.26 \pm 0.01$ \\
\hline Matrix density $\left(\mathrm{g} / \mathrm{cm}^{3}\right)$ & $\geq 1.65$ & $\begin{array}{c}1.75 \pm 0.01 \\
0 \leq 1.73\end{array}$ & $\begin{array}{c}1.75 \pm 0.01 \\
0 \leq 1.72\end{array}$ \\
\hline
\end{tabular}




\begin{tabular}{|l|c|c|c|}
\hline \multicolumn{1}{|c|}{ Property } & Specification & J52R-16-14154 & J52R-16-14155 \\
\hline $\begin{array}{l}\text { Dispersed uranium fraction (DUF) } \\
\left(\mathrm{g} \cdot \mathrm{U}_{\text {leached }} / \mathrm{g} \cdot \mathrm{U}_{\text {sample }}\right)\end{array}$ & $\leq 1.0 \mathrm{E}-5$ & $\leq 9.1 \mathrm{E}-6^{\mathrm{b}}$ & Not measured \\
\hline Attribute Properties & $\leq 0.01$ & Not measured & $\begin{array}{c}0 / 4200 \\
\leq 7.13 \mathrm{E}-4\end{array}$ \\
\hline Defective OPyC coating fraction & $\leq 5.0 \mathrm{E}-5$ & $\leq 1.0 \mathrm{E}-4^{\mathrm{b}}$ & Not measured \\
\hline $\begin{array}{l}\text { Exposed kernel fraction (EKF) } \\
\text { (kernel equiv./particle count) }\end{array}$ & $\leq 1.0 \mathrm{E}-4$ & $\leq 7.0 \mathrm{E}-5^{\mathrm{b}}$ & Not measured \\
\hline $\begin{array}{l}\text { Defective SiC coating fraction } \\
\text { (kernel equiv./particle count) }\end{array}$ & & \multicolumn{2}{|c|}{} \\
\hline $\begin{array}{l}\text { a. No compacts were used in the AGR-5/6/7 test train that failed to meet dimensional specifications for the test capsule } \\
\text { b. Pooled data for 40\% PF compacts at } 95 \% \text { confidence as analyzed by ORNL }\end{array}$ \\
\hline
\end{tabular}

The dimensions of the overcoated TRISO coated particle feed hopper, the volumetric insert, and the throat of the feed funnel in concert with the diameters of the overcoated TRISO particles contributed to variability in the quantity of particles charged to the die cavities. This is observed somewhat in the standard deviations for compact mass and compact length being greater for the $25 \%$ PF compacts than the $40 \%$ PF compacts. Development trials with TRISO particles overcoated for $10 \%$ PF compacts failed to feed reliably into the press due to incomplete insert emptying because of bridging in the feed funnel necks. 
Table 15. Characterization data for nominally $25 \%$ PF compacts after heat treatment. ${ }^{9}$

\begin{tabular}{|c|c|c|c|}
\hline Property & Specification & J52R-16-14156 & J52R-16-14157 \\
\hline \multicolumn{4}{|l|}{ Variable Properties } \\
\hline $\begin{array}{l}\text { Mean uranium loading } \\
\text { (gU/compact) } \\
\text { Nominally } 25 \% \text { packing fraction }\end{array}$ & $0.90 \pm 0.08$ & $\begin{array}{l}0.901 \pm 0.004 \\
\mathrm{LL} \geq 0.900 \\
\mathrm{UL} \leq 0.901\end{array}$ & $\begin{array}{c}0.870 \pm 0.005 \\
\mathrm{LL} \geq 0.869 \\
\mathrm{UL} \leq 0.870\end{array}$ \\
\hline Calculated PF in test train capsules & - & $0.261 \pm 0.001$ & $0.260 \pm 0.001$ \\
\hline Diameter (mm) & $\begin{array}{c}- \\
0 \leq 12.20 \\
0 \geq 12.44\end{array}$ & $\begin{array}{c}12.24 \pm 0.01 \\
0 \leq 12.20 \\
0 \geq 12.29\end{array}$ & $\begin{array}{c}12.27 \pm 0.01 \\
0 \leq 12.23 \\
0 \geq 12.31\end{array}$ \\
\hline Length $(\mathrm{mm})^{\mathrm{a}}$ & $\begin{array}{c}- \\
0 \leq 24.40 \\
0 \geq 25.30\end{array}$ & $\begin{array}{c}25.10 \pm 0.10 \\
0 \leq 24.76 \\
12 \geq 25.30\end{array}$ & $\begin{array}{c}24.78 \pm 0.13 \\
0 \leq 24.55 \\
2 \geq 25.30\end{array}$ \\
\hline Mass $(\mathrm{g})$ & - & $6.20 \pm 0.03$ & $6.09 \pm 0.04$ \\
\hline Compact density $\left(\mathrm{g} / \mathrm{cm}^{3}\right)$ & - & $2.10 \pm 0.01$ & $2.08 \pm 0.01$ \\
\hline Matrix density $\left(\mathrm{g} / \mathrm{cm}^{3}\right)$ & $\geq 1.65$ & $\begin{array}{c}1.76 \pm 0.01 \\
0 \leq 1.73\end{array}$ & $\begin{array}{c}1.75 \pm 0.01 \\
0 \leq 1.73\end{array}$ \\
\hline $\begin{array}{l}\text { Dispersed uranium fraction (DUF) } \\
\left(\mathrm{g} \cdot \mathrm{U}_{\text {leached }} / \mathrm{g} \cdot \mathrm{U}_{\text {sample }}\right)\end{array}$ & $\leq 1.0 \times 10-5$ & $\leq 1.3 \mathrm{E}-5^{b}$ & Not measured \\
\hline \multicolumn{4}{|l|}{ Attribute Properties } \\
\hline Defective OPyC coating fraction & $\leq 0.01$ & $\begin{aligned} & 0 / 4200 \\
\leq & 7.13 \mathrm{E}-4\end{aligned}$ & Not measured \\
\hline $\begin{array}{l}\text { Exposed kernel fraction (EKF) } \\
\text { (kernel equiv./particle count) }\end{array}$ & $\leq 5.0 \mathrm{E}-5$ & $\leq 3.5 \mathrm{E}-5^{b}$ & Not measured \\
\hline $\begin{array}{l}\text { Defective SiC coating fraction } \\
\text { (kernel equiv./particle count) }\end{array}$ & $\leq 1.0 \mathrm{E}-4$ & $\leq 5.7 \mathrm{E}-5^{b}$ & Not measured \\
\hline
\end{tabular}

\section{REFERENCES}

1 SPC-1352, "AGR-5/6/7 Fuel Specification"

2 J52L, Industrial Fuel Fabrication and Development - Lot J52L-16-69316, B\&W Nuclear Operations Group, Book 1, 2013.

3 ORNL/TM-2004/123, Production of Depleted $\mathrm{UO}_{2}$ Kernels for the Advanced Gas-Cooled Reactor Program for Use in TRISO Coating Development, November 2004.

4 PLN-4935, “UCO Fuel Kernel Fissure Reduction Study,” April 15, 2015.

5 PLN-4352, "Statistical Sampling Plan for AGR-5/6/7 Fuel Materials," Rev. 5, May 2016.

6 BWED 16-204, AGR-5/6/7 Overcoating and Compact Development for 25\% Packing Fraction, Summary Report / J52R, Rev. 0, July, 2016 
7 ORNL/TM-2019/1154, “Additional Confirmatory LBL Analysis of AGR-5/6/7 Compacts and OverCoated Particles," Oak Ridge National Laboratory.

8 Verbal communication with John Hunn of Oak Ridge National Laboratory.

9 J52R, Industrial Fuel Fabrication and Development - LEU Compact Certification Package, BWX Technologies, Book 1, 2017. 
Appendix A

Jet Pulverizer Co. Certificates of Analysis - Resinated Graphite Powder 


\section{Appendix A}

\section{Jet Pulverizer Co. Certificates of Analysis - Resinated Graphite Powder}

\section{CERTIFICATE OF ANALYSIS}

DATE:

COMPANY:

PRODUCT:

CUSTOMER ORDER NO.:

SAMPLE DATE:

LOT NO.:
July 19,2016

Idaho National Labs

Graphite Resin Blend Jet milled

Contract \#00172087

July 12,2016

Mfg: 07/12/16

\begin{tabular}{|c|c|c|}
\hline TEST METHOD & SPECIFICATION & RESULTS \\
\hline Horiba LA 950 & $7-15 \mu \mathrm{d50}$ & $8.61 \mu \mathrm{d50}$ \\
\hline & & \\
\hline
\end{tabular}

Notes: Four different raw materials were pre-blended in specific mass ratios as provided by INL. After blending, the material was jet milled and packed into 643 gallon drums with temperature indicator cards.

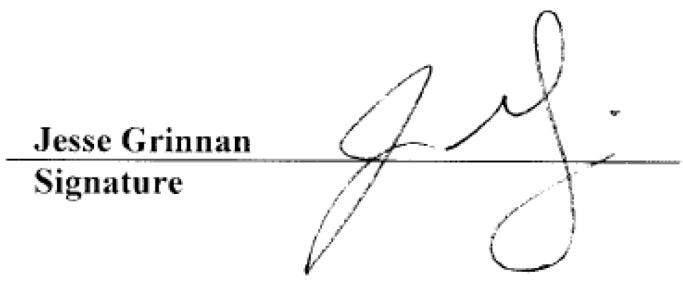




\section{CERTIFICATE OF ANALYSIS}

DATE:

COMPANY:

PRODUCT:

CUSTOMER ORDER NO.:

SAMPLE DATE:

LOT NO.:
July 19,2016

Idaho National Labs

\section{Graphite Resin Blend Mass Statement}

Contract \#00172087

July 12, 2016

See below

\begin{tabular}{|l|c|c|}
\hline \multicolumn{1}{|c|}{ PRODUCT ID } & WT FRACTION & MASS WEIGHED \\
\hline \multicolumn{1}{|c|}{ BLEND RATIOS FOR 13-42 LB BLENDS } \\
\hline $\begin{array}{l}\text { Asbury 3482 Flake Carbon } \\
\text { Lot: } 10521\end{array}$ & $64 \%$ & $25.60 \mathrm{lbs}$ \\
\hline $\begin{array}{l}\text { SGL KRB2000 Graphite } \\
\text { Lot: 731204 }\end{array}$ & $16 \%$ & $6.40 \mathrm{lbs}$ \\
\hline $\begin{array}{l}\text { Durite SD 1708 Resin } \\
\text { Lot: LK6DC0052, LK6EC0069 }\end{array}$ & $19 \%$ & $7.60 \mathrm{lbs}$ \\
\hline $\begin{array}{l}\text { Hexamethylenetetramine } \\
\text { Lot: } 151729\end{array}$ & $1 \%$ & $0.40 \mathrm{lbs}$ \\
\hline
\end{tabular}

Notes: All four parts were blended in separate $40 \mathrm{lb}$ batches prior to millifig.

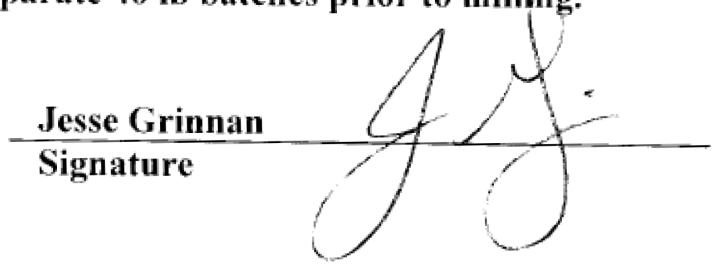




\section{CERTIFICATE OF ANALYSIS}

DATE:

COMPANY:

PRODUCT:

CUSTOMER ORDER NO.:

SAMPLE DATE:

LOT NO.:
July 19, 2016

Idaho National Labs

Graphite Resin Blend RAW Materials

Contract \#00172087

July 12, 2016

See product ID below

\begin{tabular}{|c|c|c|c|}
\hline Product & $\begin{array}{c}\text { TEST } \\
\text { METHOD }\end{array}$ & State & RESULTS \\
\hline $\begin{array}{c}\text { Asbury 3482 } \\
\text { Lot: 10521 }\end{array}$ & Horiba LA 950 & Small Flakes & $160.10 \mu$ d50 \\
\hline $\begin{array}{c}\text { SGL KRB 2000 Graphite } \\
\text { Lot: 731204 }\end{array}$ & Horiba LA 950 & Fine powder & $22.69 \mu$ d50 \\
\hline $\begin{array}{c}\text { Durite SD-1708 Resin } \\
\text { Lot: LK6DC0052, } \\
\text { LK6EC0069 }\end{array}$ & Horiba LA 950 & $\begin{array}{c}\text { 1/2" to 2" pieces } \\
\text { pre-crushed/milled }\end{array}$ & $2.36 \mu$ d50 \\
\hline $\begin{array}{c}\text { Hexamethylenetetramine } \\
\text { Lot: 151729 }\end{array}$ & Microscope & $\begin{array}{c}\text { Granular in chunks } \\
\text { Screened <20 mesh }\end{array}$ & $700 \mu$ Granules \\
\hline Blend in Raw state & Horiba LA 950 & As above blended & $99.38 \mu$ d50 \\
\hline
\end{tabular}

Notes: Supplied raw materials before being blended, except the Durite Resin. Durite Resin was in large $1 / 2$ " to 1 " flakes which were pre-crushed and jet milled prior to blending.

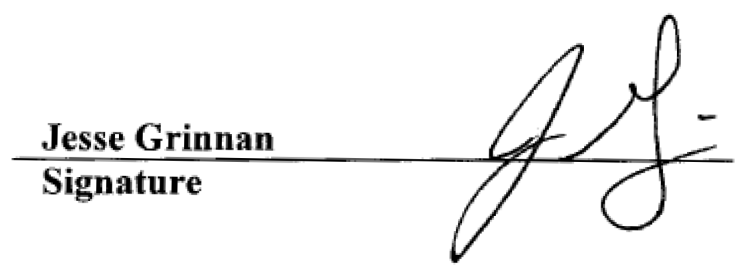

